NASA-CR-204681

\title{
Manifestations of Dynamic Strain Aging in Soft-Oriented NiAl Single Crystals
}

\author{
M.L. WEAVER, M.J. KAUFMAN, and R.D. NOEBE
}

\begin{abstract}
The tensile and compressive properties of six NiAl-base single-crystal alloys have been investigated at temperatures between 77 and $1200 \mathrm{~K}$. The normalized critical resolved shear stresses (CRSS/E) and work-hardening rates $(\theta / E)$ for these alloys generally decreased with increasing temperature. However, anomalous peaks or plateaus for these properties were observed in conventional purity (CPNiAl), Si-doped (NiAl-Si), C-doped low Si (UF-NiAll), and Mo-doped (NiAl-Mo) alloys at intermediate temperatures (600 to $1000 \mathrm{~K}$ ). This anomalous behavior was not observed in highpurity, low interstitial material (HP-NiAl). Low or negative strain-rate sensitivities (SRS) also were observed in all six alloys in this intermediate temperature range. Coincident with the occurrence of negative strain-rate sensitivities was the observation of serrated stress-strain curves in the CPNiAl and NiAl-Si alloys. These phenomena have been attributed to dynamic strain aging (DSA). Chemical analysis of the alloys used in this study suggests that the main specie responsible for strain aging in $\mathrm{NiAl}$ is $\mathrm{C}$ but indicate that residual $\mathrm{Si}$ impurities can enhance the strain aging effects. The corresponding dislocation microstructures at low temperatures $(300$ to $600 \mathrm{~K}$ ) were composed of welldefined cells. At intermediate temperatures $(600$ to $900 \mathrm{~K}$ ), either poorly defined cells or coarse bands of localized slip, reminiscent of the vein structures observed in low-cycle fatigue specimens deformed in the DSA regime, were observed in conventional purity, Si-doped, and in Mo-doped alloys. In contrast, a well-defined cell structure persisted in the low interstitial, high-purity alloy. At elevated temperatures $(\geq 1000 \mathrm{~K})$, more uniformly distributed dislocations and sub-boundaries were observed in all alloys. These observations are consistent with the occurrence of DSA in NiAl singlecrystal alloys at intermediate temperatures.
\end{abstract}

\section{INTRODUCTION}

SEVERAL manifestations of strain aging have been identified as playing a role in the deformation of polycrystalline and single-crystal NiAl. They include the following: (1) the occurrence of yield points; $;^{[1-A]}$ (2) serrated stress-strain curves; ; $^{[1.5-10]}$ (3) strain-rate sensitivity minima; [11.12] (4) yield stress plateaus as a function of temperature; ${ }^{[13]}(5)$ the occurrence of local maxima or plateaus in plots of work-hardening rate $(\theta)$ as a function of temperature; $[11,14]$ and (6) flow stress transients on changes in strainrate. ${ }^{|12.15|}$ Despite these observations, the significance of strain aging and its influence on the mechanical properties of NiAl have, until recently, been largely ignored. Lately, Hack and co-workers ${ }^{[3.69 .16-18]}$ have observed that the fracture toughness of soft-oriented single crystals is extremely sensitive to heat treatments in the 473 to $673 \mathrm{~K}$ range. For example, they observed that slow cooling through this temperature regime resulted in brittle specimens with low fracture toughness $(\approx 4 \mathrm{MPa} \sqrt{\mathrm{m}})$, whereas fast cooling resulted in an increased fracture toughness $(\approx 16 \mathrm{MPa} \sqrt{\mathrm{m}})$ and more ductile behavior. They attributed the reduction in ductility

M.L. WEAVER, formerly Graduate Student, Department of Materials Science and Engineering. University of Florida, is Research Associate, Center for Nonlinear and Nonequilibrium Aeroscience, Florida A \& $M$ University, Tallahassee, FL 323306, and the Center for Materials Research and Technology, Florida State University, Tallahassee, FL 32310. M.J. KAUFMAN, Associate Professor, is with the Department of Materials Science and Engineering, University of Florida, Gainesville, FL 32611. R.D. NOEBE, Materials Research Engineer, Materials Division NASALewis Research Center, Cleveland, OH 44135.

Manuscript submitted August 7, 1995. during slow cooling to static strain aging (SSA), which is a time-dependent process that results when solute atoms segregate to the strain fields around dislocations causing pinning. Similar observations have been made for polycrystalline NiAl. For example, Margevicius et al ${ }^{[2]}$ observed that sharp upper yield points can be induced in conventional-purity binary $\mathrm{NiAl}$ by fumace cooling a cast and extruded or prestrained alloy from $1100 \mathrm{~K}$ to room temperature. Furthermore, Weaver et al. [14.15.19-21] showed that the magnitude of the yield point increased with aging time according to a $t^{2 / 3}$ relationship in conventional purity and carbon-doped NiAl, and reported the occurrence of serrated flow. Further evidence supporting the occurrence of strain aging was provided by the observations of serrated flow in these same conventional purity NiAl polycrystals and single crystals at elevated temperatures $(>700 \mathrm{~K})$ and the lack of such serrations in high-purity materials. ${ }^{[5.699 .15-18.22]}$

The purpose of this article is to thoroughly describe the dynamic strain aging (DSA) behavior observed in $\mathrm{NiAl}$ single crystals and to identify the species responsible. To accomplish these objectives, nominally stoichiometric $\mathrm{NiAl}$ single crystals with differing interstitial contents were studied. Since dilute additions of reactive elements have been reported to retard the strain-aging behavior in body-centered cubic (bcc) metals, an alloy intentionally doped with Mo also was investigated to analyze the role of a strong gettering agent on the strain-aging behavior of $\mathrm{NiAl}$ single crystals. Because $\mathrm{Si}$ is a common impurity in conventionalpurity NiAl single crystals due to interaction with aluminasilicate shell molds during directional solidification, an alloy containing an intentional addition of $\mathrm{Si}$ also was investigated to ascertain the role of this substitutional impurity on the deformation behavior of $\mathrm{NiAl}$. 
Table I. Chemical Compositions and Crystallographic Orientations of the Single-Crystal Alloys Examined in This Study

\begin{tabular}{|c|c|c|c|c|c|c|c|c|c|}
\hline \multirow[b]{2}{*}{ Alloy Ingot } & \multirow[b]{2}{*}[hkl]{} & \multicolumn{4}{|c|}{ At. Pct } & \multicolumn{4}{|c|}{ Interstitials (At. Ppm) } \\
\hline & & $\mathrm{Ni}$ & Al & Mo & Si & $\mathbf{C}$ & $\mathbf{O}$ & $\mathbf{N}$ & $\mathbf{S}$ \\
\hline HP-NiA] UT-HP2 & [123] & $50.2 \pm 0.2$ & $49.8 \pm 0.2$ & - & 0.04 & 76 & 40 & 24 & $<10$ \\
\hline CPNiAl-1 D5-553 & [123] & $50.6 \pm 0.2$ & $49.2 \pm 0.2$ & - & 0.17 & 112 & 87 & $<6$ & $<10$ \\
\hline CPNiAl-2 DS-1273 & {$[110]$} & $50.4 \pm 0.2$ & $49.4 \pm 0.2$ & - & 0.15 & 209 & 612 & $<6$ & $<10$ \\
\hline UF-NiAll UF-001 & [123] & $50.3 \pm 0.2$ & $49.3 \pm 0.2$ & - & 0.01 & 136 & 132 & 15 & $<10$ \\
\hline NiAl-Mo D52-783 & [123] & $50.0 \pm 0.2$ & $49.8 \pm 0.2$ & 0.11 & 0.23 & 558 & 316 & 25 & $<10$ \\
\hline NiAl-Si UF-003 & [110] & $50.4 \pm 0.2$ & $49.3 \pm 0.2$ & - & 0.29 & 220 & 95 & 12 & $<10$ \\
\hline
\end{tabular}

$\mathrm{Ni}$ and Al Analysis performed using wet chemistry/titration techniques, relative accuracy $\pm 1 \mathrm{pct}$.

Mo Analysis performed on a flame atomic absorption emission spectrophotometer, Perkin-Elmer model 5000 (Perkin-Elmer Physical Electronics, Eden Prairie, MN), relative accuracy \pm 5 pct.

C and S Analysis performed on a simultaneous carbon/sulfur determinator, LECO Corporation (St. Joseph, MI), model CS-244, relative accuracy \pm 10 pct.

$\mathrm{N}$ and $\mathrm{O}$ Analysis performed on a simultaneous nitrogen/oxygen determinator, LECO Corp., model TC-136 or model TC -436 , relative accuracy \pm 10 pct.

Si Analysis performed on an ultravioletvisible spectrophotometer, Shimadzu, Columbia, MD, model UV-160, relative accuracy \pm 10 pct.

\section{EXPERIMENTAL}

One Mo-doped (NiAl-Mo), one Si-doped (NiAl-Si), and three nominally stoichiometric NiAl (CPNiAl-1, CPNiAl-2, and UF-NiAl1) single-crystal slabs were grown under an argon atmosphere by a Bridgman procedure. Slabs CPNiAl-1, CPNiAl-2, and NiAl-Mo were produced at General Electric Aircraft Engines (Cincinnati, $\mathrm{OH}$ ), using alumina-silicate shell molds and measured $25 \times 32 \times 100 \mathrm{~mm}$. Slabs UF$\mathrm{NiAll}$ and $\mathrm{NiAl}-\mathrm{Si}$ were produced at the University of Florida (Gainesville, FL) using high-purity alumina crucibles and measured $25-\mathrm{mm}$ diameter $\times 60-\mathrm{mm}$ length. A low interstitial, high-purity ingot of stoichiometric NiAl (HP-NiAl), 25$\mathrm{mm}$ diameter $\times 50-\mathrm{mm}$ length, was produced via a containerless electromagnetic levitating zone process at the University of Tennessee (Knoxville, TN). All slabs were homogenized at $1589 \mathrm{~K}$ for at least $\mathrm{I}$ hour in argon, followed by fumace cooling to room-temperature prior to machining into test specimens.

Postprocessing chemical analyses were conducted using the techniques deemed the most accurate for the particular elements. The results of these analyses are listed in Table I. The crystals were oriented using the back-reflection Laue technique and either ground into round button-head tensile specimens parallel to the $\langle 123\rangle$ axis or (EDM) wire cut into cylindrical compression specimens parallel to the $(123\rangle$ or (110) axis. Specimen dimensions were (1) 3.1 and $30.0 \mathrm{~mm}$ for the tensile gage diameter and gage length and (2) 3.0 $\mathrm{mm}$ and $6.4 \mathrm{~mm}$ for the compression sample diameter and height, respectively. All tensile specimens were electropolished prior to testing in a 10 pct perchloric acid-90 pct methanol solution that was cooled to $208 \mathrm{~K}$.

All mechanical tests were performed on an Instron Model 1125 load frame at constant crosshead velocities corresponding to initial strain rates ranging from $2.8 \times 10^{-5} \mathrm{~s}^{-1}$ to $2.8 \times 10^{-4} \mathrm{~s}^{-1}$. Tests between 300 and $1100 \mathrm{~K}$ were run in air by heating the samples in a clamshell-type resistance furnace. Testing below room temperature was accomplished in compression by cooling in liquid baths. True stress-strain data were calculated from the load-time plots and yield stresses were determined by the 0.2 pct offset method. During some of the elevated-temperature compression tests, strain was measured using a clip-on strain gage extensometer attached to a compression cage. The strain-rate sensitivity (SRS) was determined by increasing the strain rate by a factor of ten from the base strain rate at fixed plastic strain intervals. The quantity extracted from these experiments was the SRS, $s=\Delta \sigma / \Delta \ln \dot{\varepsilon}$.

Samples for transmission electron microscopy (TEM) were cut from the tested tensile or compression specimens with a low-speed diamond saw and twin-jet electropolished in a solution of $70 \mathrm{pct}$ ethanol, $14 \mathrm{pct}$ distilled water, 10 pct butylcellusolve, and 6 pct perchloric acid at $273 \mathrm{~K}$, $25 \mathrm{~V}$, and $0.15 \mathrm{~mA}$. The TEM examinations were conducted in a modified JEOL* $100 \mathrm{C}$ microscope operating at an ac-

*JEOL is a trademark of Japan Electron Optics Limited, Tokyo.

celerating voltage of $120 \mathrm{kV}$.

\section{RESULTS}

\section{A. Composition and Microstructure}

The results of the chemical analyses indicated that within experimental accuracy, the $\mathrm{Ni}$ and $\mathrm{Al}$ contents of the six alloys are not significantly different from one another. The major differences between the materials are the residual $\mathrm{Si}$, $\mathrm{C}, \mathrm{O}$, and $\mathrm{N}$ contents and the addition of 0.1 at. pet Mo to $\mathrm{NiAl}-\mathrm{Mo}$, which resulted in the formation of coarse precipitates (Figure 1). The results of energy-dispersive spectroscopic analysis and TEM microdiffraction indicated that these particles were $\mathrm{Mo}_{2} \mathrm{C}$. The presence of silicon in NiAl$\mathrm{Mo}, \mathrm{CPNiAl}-1$, and CPNiAl-2 has been attributed to reaction between the melt and the ceramic shell molds during processing. The lack of $\mathrm{Si}$ in UF-NiAll has been attributed to the use of arc-melted as opposed to vacuum-inductionmelted feed stock and the use of higher purity crucibles during directional solidification.

\section{B. Mechanical Properties}

The temperature-dependent properties (i.e., critical resolved shear stress at 0.2 pct strain (CRSS), work-hardening rate evaluated over the range 0.2 to 1.8 pct plastic strain, and SRS evaluated at 1.8 and 5.0 pct plastic strain have been determined for all six alloys and are summarized in Figures 2 and 3. Work-hardening and SRS parameters were 

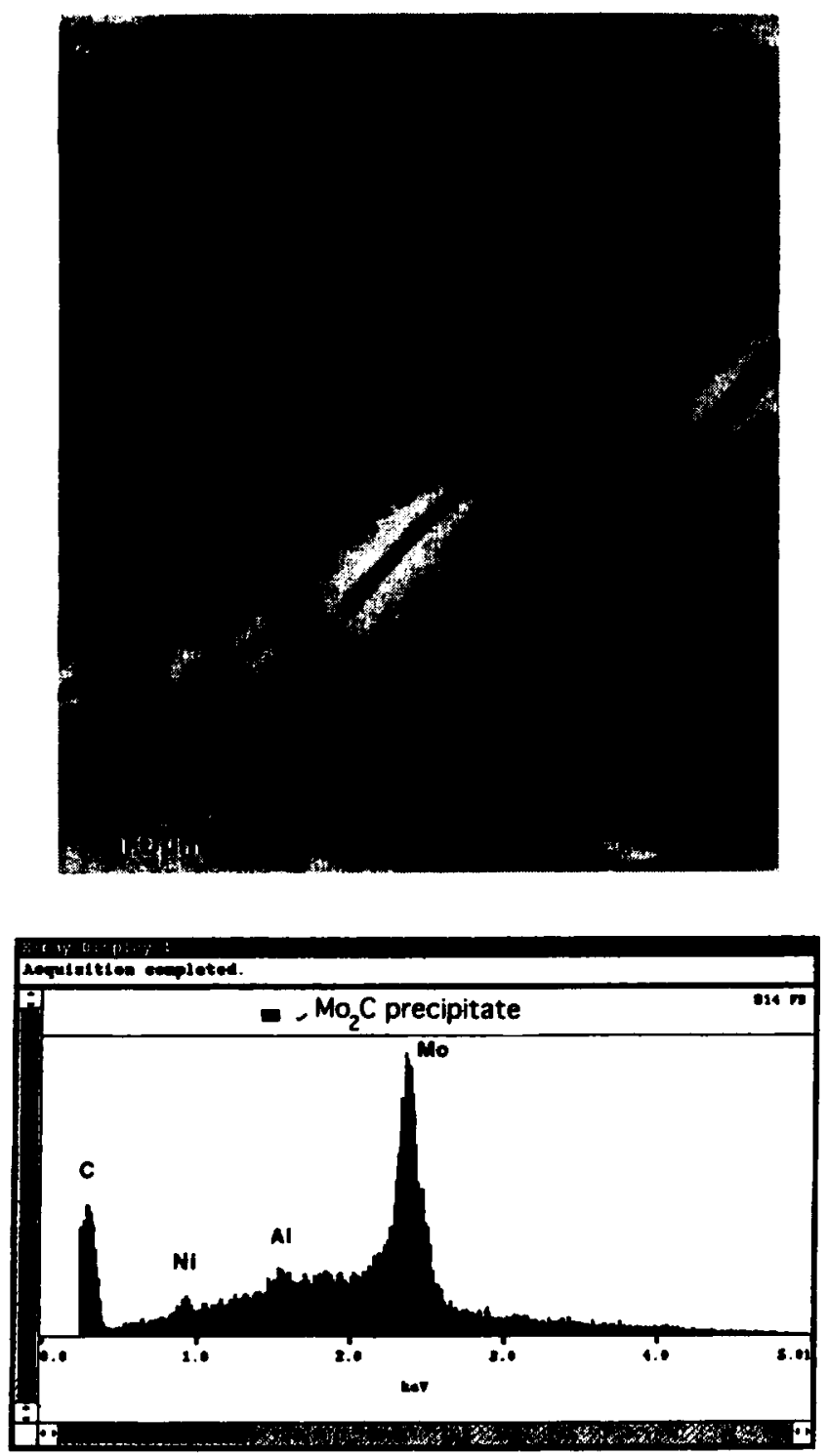

not measured at higher strains due to limited tensile ductility at lower temperatures and due to pronounced barreling after approximately 5.0 pct deformation in compression. Figure 2 shows the temperature dependence of the CRSS at 0.2 pct plastic strain and the work-hardening characteristics for all six alloys. The work-hardening characteristics of these materials have been evaluated from the average work-hardening rate $(\theta=\Delta \sigma / \Delta \varepsilon)$. As noted by Kocks, ${ }^{[23]}$ in most materials, flow stress and $\theta$ decrease in a monotonic fashion with increasing temperature, in part because the shear and elastic moduli also decrease with increasing temperature and contribute negatively to the flow stress. Consequently, in cases where the temperature dependence of the elastic modulus, for example, is sufficiently negative, relatively slight positive contributions from DSA can be masked by modulus effects. As a result, the work-hardening and CRSS results presented in Figure 2 have been normalized with respect to the elastic modulus $E$. Since no estimates of $E$ for $\langle 123\rangle$-oriented single crystals $\left(E_{123}\right)$ were available, it was assumed that $E_{123}$ was equivalent to $E$ for (111)-oriented single crystals $\left(E_{111}\right)$, as determined by Wasilewskji24] (i.e., $E_{123} \equiv E_{111}$ ).
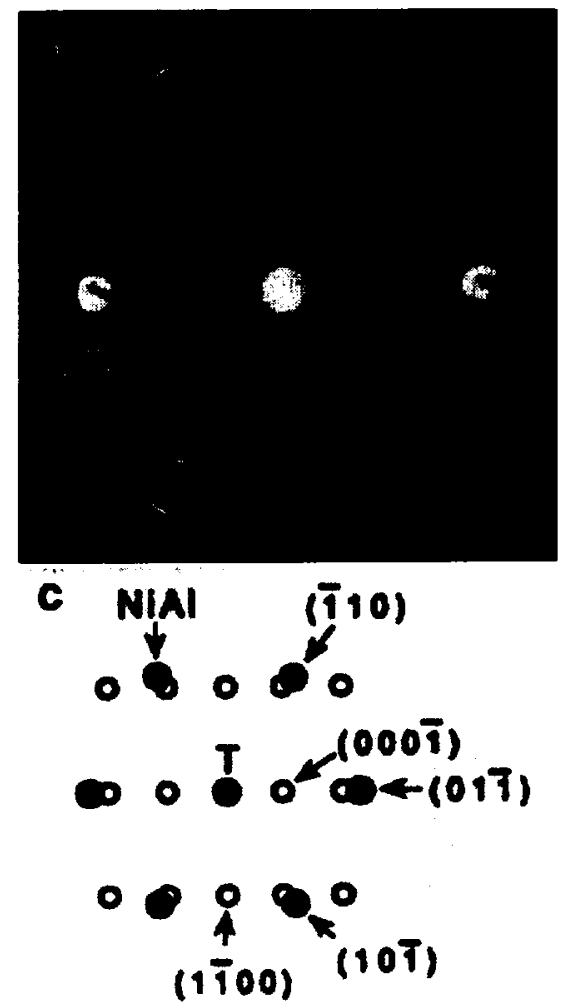

Fig. 1-Precipitates observed in NiAl-Mo: $(a)$ bright-field TEM micrograph of $\mathrm{Mo}_{2} \mathrm{C}$ precipitates in NiAl-Mo; $(b)$ TEM microdiffraction pattern illustrating an orientation relationship of $\left.[111]_{\mathrm{Nux}} / / 11 \overline{2} 0\right]_{\mathrm{M}, 1 \mathrm{C}}$ and $(01 \overline{1})_{\text {NiA }} / /(000 \bar{l})_{\text {Mor. }}$. between the precipitate and NiAl matrix; $(c)$ a schematic representation of (b); and (d) SEM EDS spectra for one of the precipitates indicating that they contain Mo and $\mathrm{C}$.

In agreement with prior investigations on single-crystal and polycrystalline $\mathrm{NiAl}$ as reviewed in References 13, 25, and 26 , both the CRSS/ $E$ and the $\theta / E$ generally decreased with increasing temperature. However, in CPNiAl-1, CPNiAl-2, UF-NiAl1, NiAl-Mo, and NiAl-Si, apparent plateaus or peaks were observed in the temperature range of 650 to $1000 \mathrm{~K}$. In HP-NiAl, however, no such plateau was observed, in agreement with the previous observations on a similarly processed material. ${ }^{(15.27)}$ Figures 4 and 5 show portions of load-elongation curves for $\mathrm{NiAl}-\mathrm{Si}, \mathrm{HP}-\mathrm{NiAl}$, and UF-NiAll following uniaxial deformation and strainrate change tests performed at various temperatures. In NiAl-Si (Figure 4), serrated flow was observed in the load-elongation curves at temperatures below those associated with the apparent plateaus or peaks in CRSS. Similar observations were made in CPNiAl-1 and CPNiAl-2, while no serrated flow was observed in UF-NiAll1, NiAl-Mo, or in HP-NiAl. The occurrence of serrated flow has been previously reported in NiAl. ${ }^{[5-7.9 .17]}$ Since serrated flow can be associated with DSA and the Portevin-Le Chatelier (PLC) effect, the SRS has been deduced from strain-rate change tests. The temperature dependence of the strain-rate sensi- 


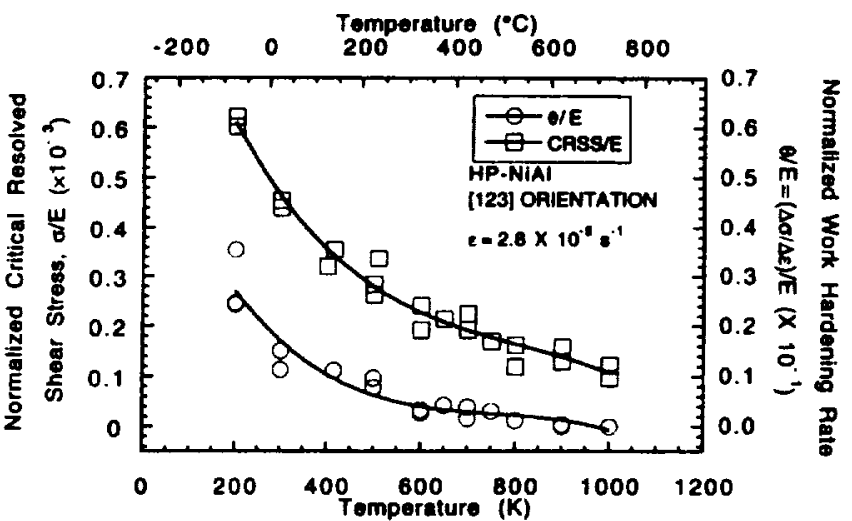

(a)



(c)

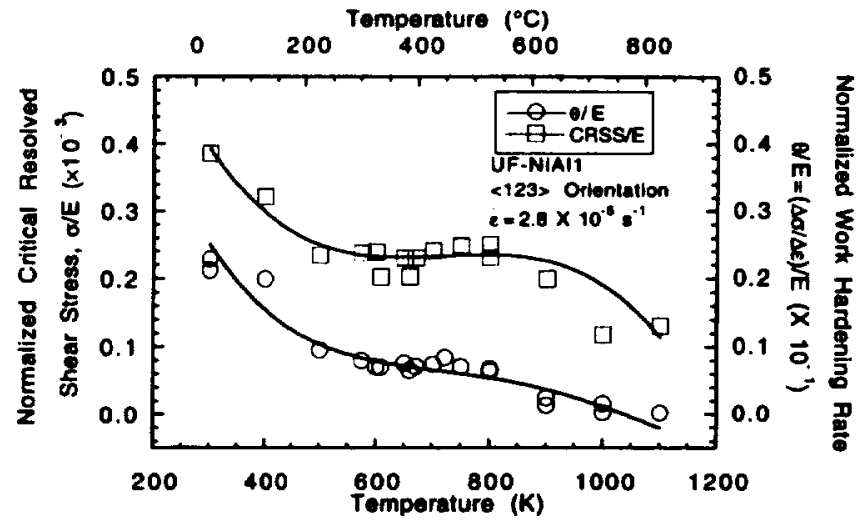

(e)

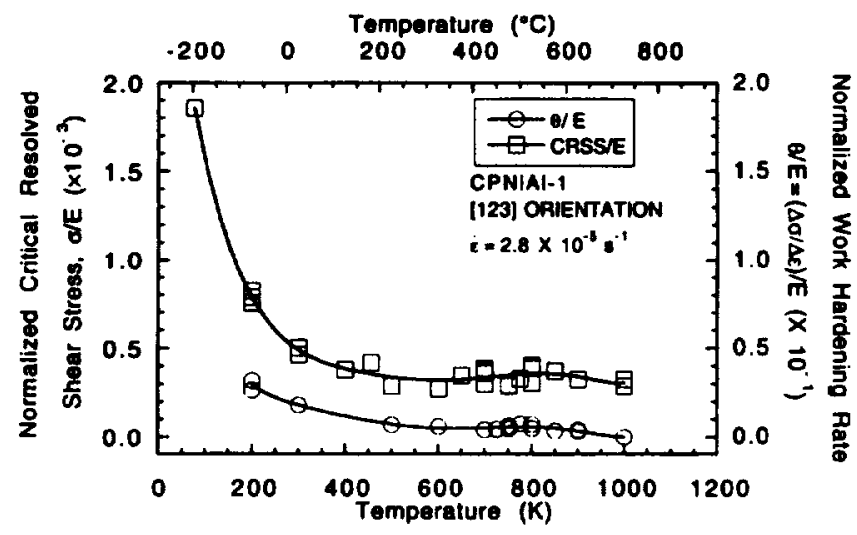

(b)

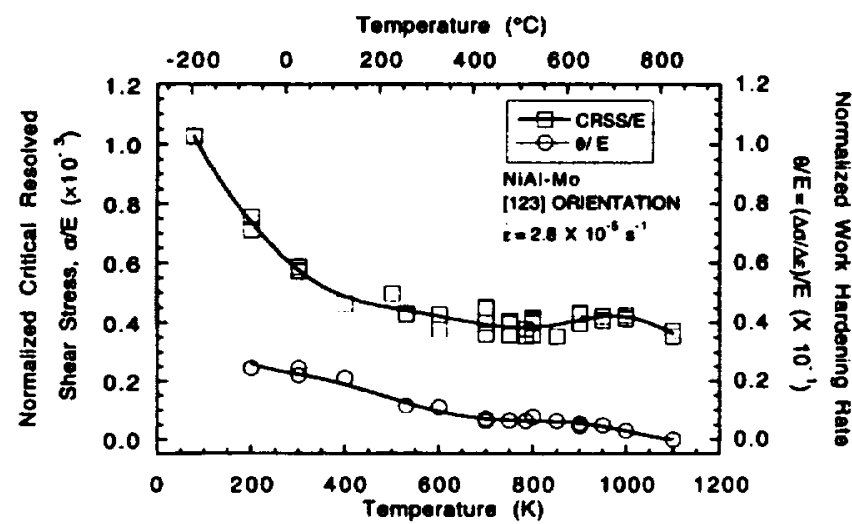

(d)



(f)

Fig. 2-Temperature dependence of the normalized CRSS at 0.2 pct strain and work hardening rate, $\theta E$, for NiAl single crystals: (a) HP-NiAl; (b) CPNiAl-I; (c) CPNiAl-2; (d) NiAl-Mo; (e) UF-NiAll; and (f) NiAl-Si.

tivity is presented in Figure 3. For all six alloys, SRS exhibits distinct local minimums in the temperature ranges 300 to $400 \mathrm{~K}$ (low temperature) and 600 to $800 \mathrm{~K}$ (intermediate temperature), with $s$ actually becoming negative for CPNiAl-1, CPNiAl-2, and NiAl-Si at 1.8 pct and at $\sim 5.0$ pct strain in the intermediate temperature range. Coincident with those temperatures where a negative SRS was observed was the occurrence of the aforementioned serrated yielding. In addition to the studies mentioned previously, recent independent analyses of conventional-purity NiAl[16.18]

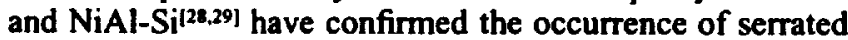
flow at intermediate temperatures. In addition, Winton et al., ${ }^{(2828)}$ who have performed strain-rate change experiments on $\mathrm{NiAl}-\mathrm{Si}$ at higher strains, have confirmed the existence of a pronounced SRS minimum at intermediate temperatures where SRS approached zero but tended to remain slightly positive. In UF-NiAll and NiAl-Mo, where SRS remained positive, flow stress transients in the form of sharp upper yield points were observed, whereas no such transients were observed in $\mathrm{HP}-\mathrm{NiAl}$ in this temperature regime. In the low-temperature interval, however, diffuse flow-stress transients were consistently observed in HP$\mathrm{NiAl}$ and in UF-NiAll with the later exhibiting the most pronounced effects (Figures 5(b) and (c)). No low temperature transients were exhibited by CPNiAl-1, CPNiAl-2, NiAl-Mo, or NiAl-Si.

Serrated yielding typically occurred after a small critical plastic strain $\varepsilon_{\mathrm{c}}$. The temperature $T$ and strain-rate $\dot{\varepsilon}$ de- 


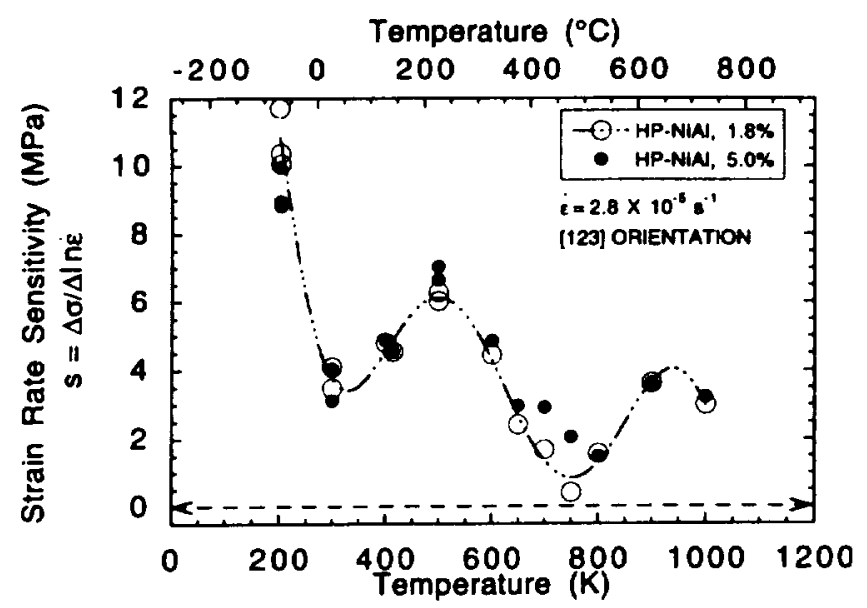

(a)

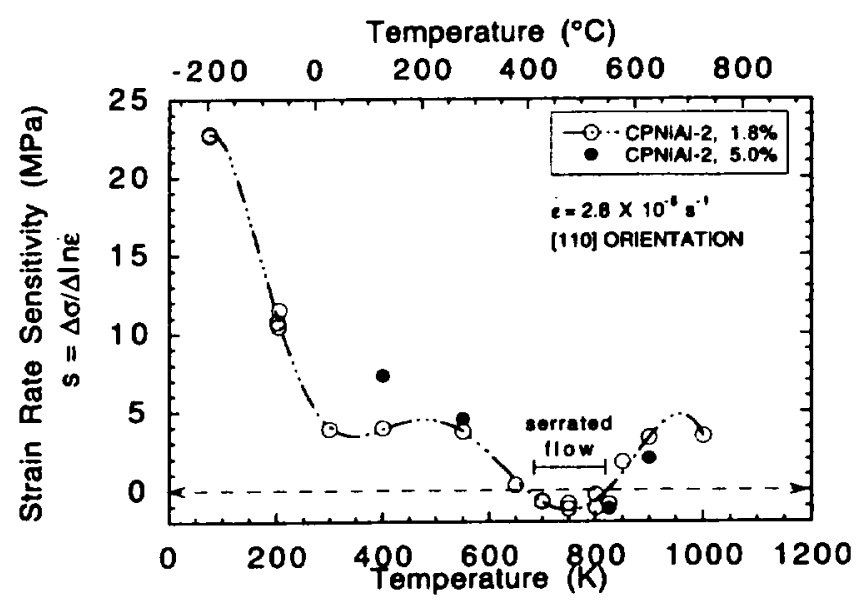

(c)

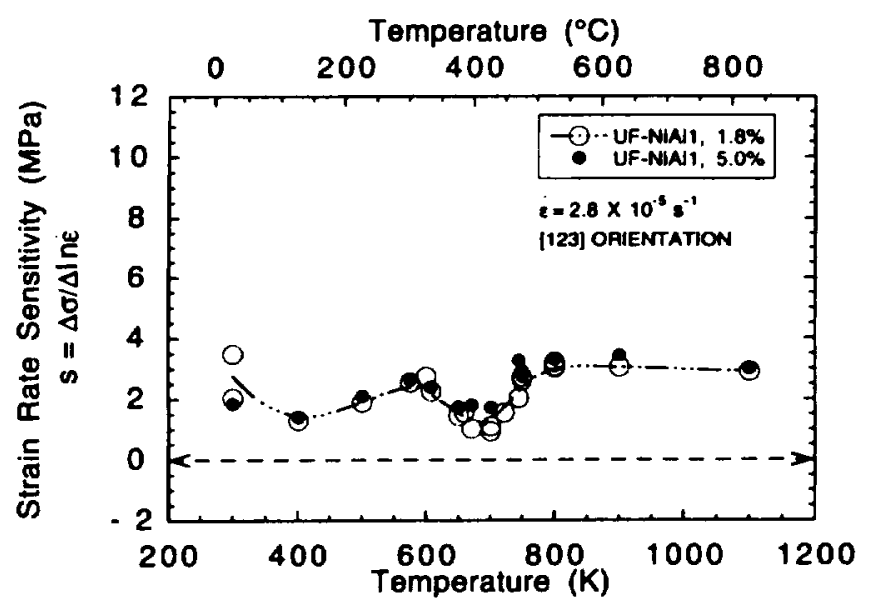

(e)



(b)

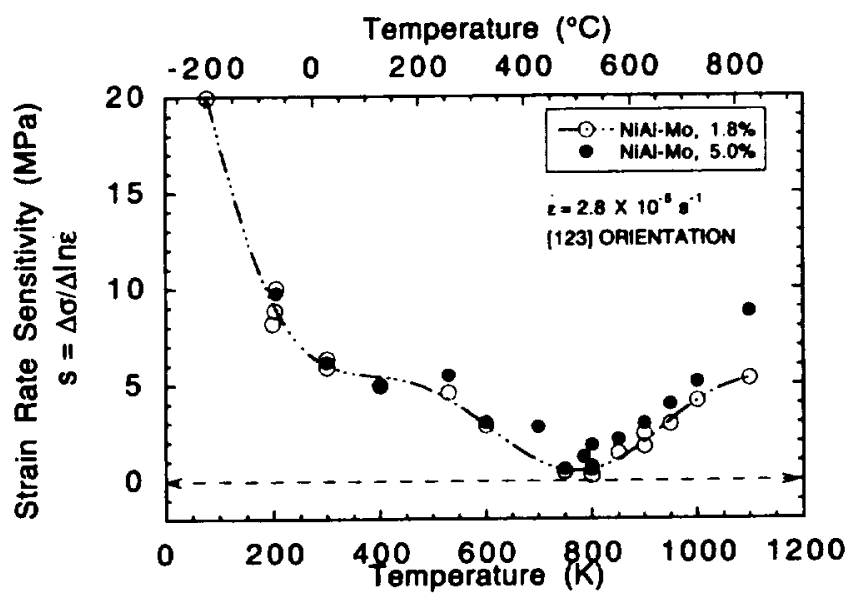

(d)

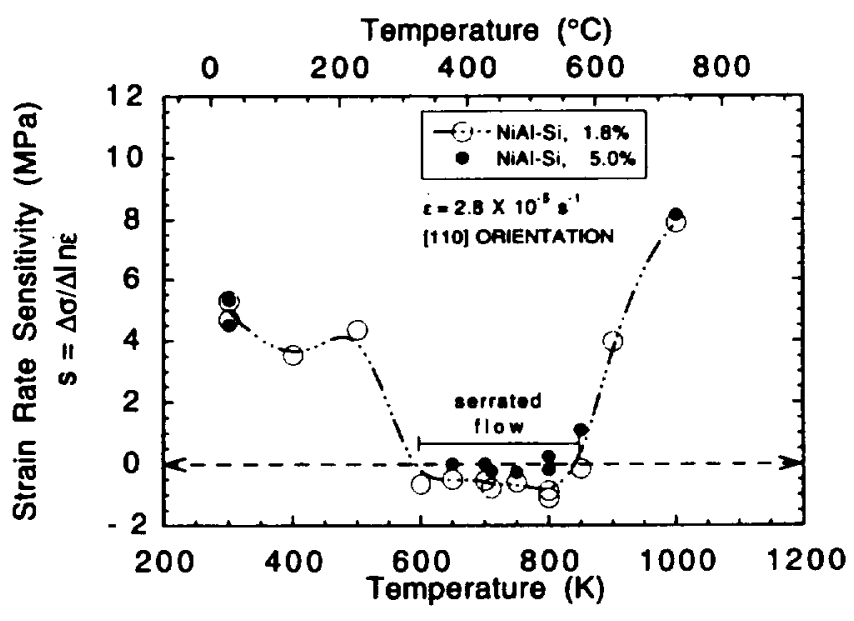

(f)

Fig. 3-Temperature dependence of SRS for NiAl single crystals: (a) HP-NiAl; (b) CPNiAl-1; (c) CPNiAl-2; (d) NiAl-Mo; (e) UF-NiAll; and (n) NiAl$\mathrm{Si}$.

pendence of $\varepsilon_{c}$ for CPNiAl-1, CPNiAl-2, and NiAl-Si is shown in Figure 6. Serrations occur in only certain $\varepsilon$ and $T$ regimes. Within these regions, the magnitude of $\varepsilon_{c}$ increased with increasing $\dot{\varepsilon}$. The magnitude of $\varepsilon_{\mathrm{c}}$ also was dependent upon temperature. Increasing $T$ resulted in a steady decrease in $\varepsilon_{\mathrm{c}}$ to a local minimum, followed by a rapid increase with further increases in temperature. A clearer indication of the conditions under which serrated flow occurs is shown in Figure 7, which maps the strainrate-temperature regime where serrated flow occurs in CPNiAl-1, CPNiAl-2, and NiAl-Si. Using the classification scheme of Rodriguez, ${ }^{(30)}$ the serrations in the region where a negative temperature dependence of the critical strain was observed could be predominantly classified as a mixture of type $\mathrm{C}$, while the lower temperature (i.e., below $800 \mathrm{~K}$ ) serrations could be classified as type B (Figure 4(a)). Both 


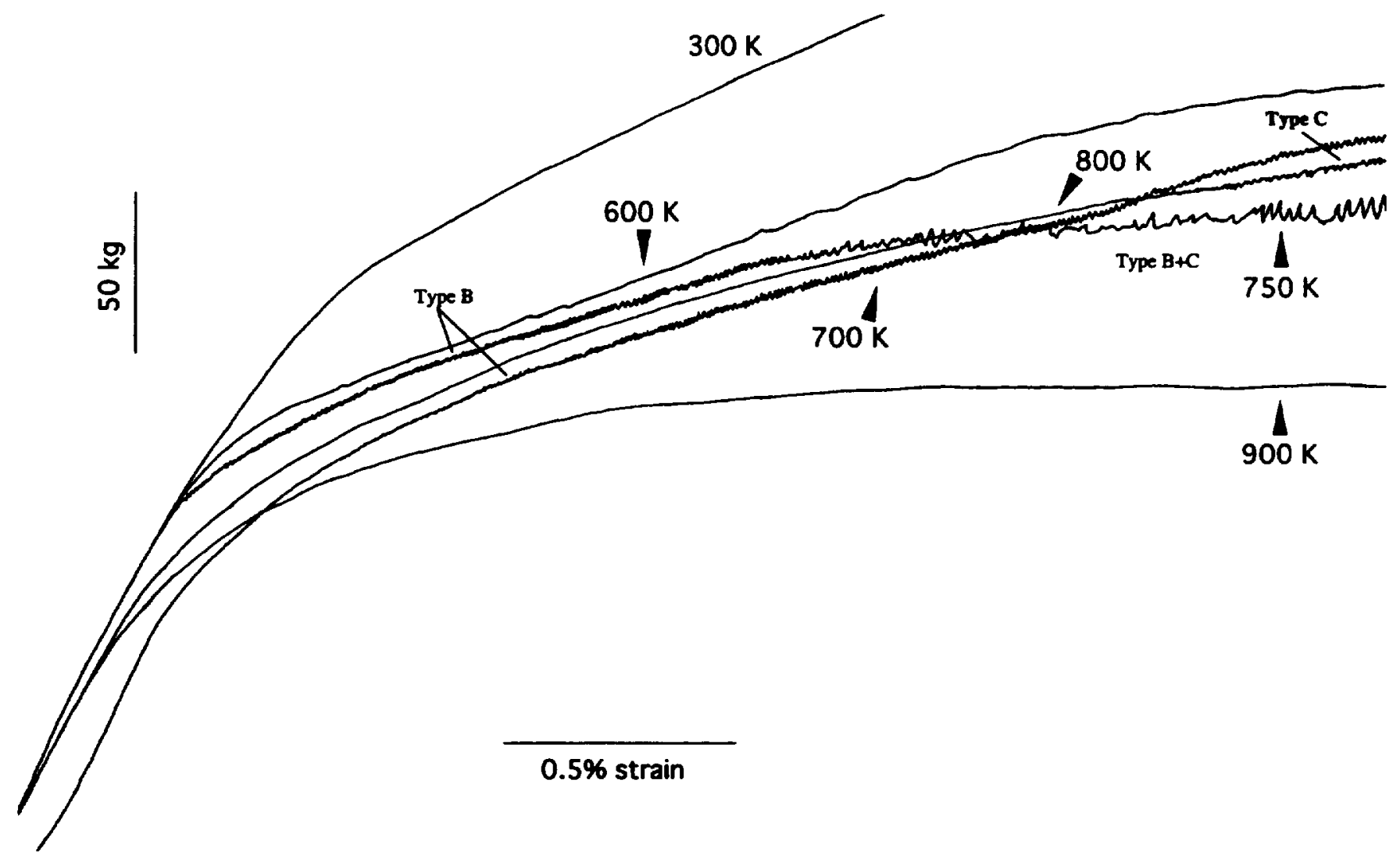

(a)



(b)

Fig. 4-The effect of temperature on the shape of the flow curves in Sidoped NiAl deformed at $\dot{\varepsilon}=2.8 \times 10^{-5} \mathrm{~s}^{-1}$. (a) and $(b) \mathrm{NiAl}-\mathrm{Si}$ following uniaxial deformation and strain-rate change experiments conducted near 5 pct plastic strain. Note the transition from type-B serrations at lower temperatures to type-C serrations at higher temperatures and strains. Similar flow curves were observed for CPNiAl-1 and CPNiAl-2.

$$
\varepsilon_{2}=2.8 \times 10^{-4} \mathrm{~s}^{-1}
$$


types of serrations are characteristic of unlocking of pinned dislocations and are associated with discontinuous deformation band propagation.

In this investigation the activation energy $Q$ for serrated flow was ascertained via three distinct methods. In the first method, the critical plastic strain was related to $\mathcal{E}$ and $T$ by the following equation: ${ }^{[30.31]}$

$$
\varepsilon_{c}^{(m+\beta)}=K \dot{\varepsilon} \exp (Q / R T)
$$

where $m$ and $\beta$ are exponents related to the variation in vacancy concentration $C_{v}$ and mobile dislocation density $\rho_{m}$ (i.e., $C_{v} \propto \varepsilon^{m}$ and $\rho_{m} \propto \mathcal{E}^{\beta}$ ), $K$ is a constant, and $\mathrm{R}$ and $T$ have their usual meanings. The exponent $(m+\beta)$, determined from the slope of the plot of $\ln \dot{\varepsilon} v s \ln \varepsilon_{c}$ at a constant temperature (Figure 6(a)), was in the range 0.93 to 1.27 for CPNiAl-1, CPNiAl-2, and NiAl-Si. The activation energy is then determined from a plot of $\ln \varepsilon_{c} v s$ 1/RT (Figure 6(b) $)^{[32.33]}$ (i.e., $Q=$ slope $\left.\times(m+\beta)\right)$. This method produces activation energies in the range 71 to $94 \mathrm{~kJ} / \mathrm{mol}$ for the onset of serrated flow over the temperature range where $\varepsilon_{c}$ decreases with increasing temperature.

In the second method, $Q$ can be determined from the slope of an Arrhenius plot of $\ln \varepsilon$ vs 1/RT for conditions where serrated yielding occurs. In this case, the onset lines marking the beginning of serrated flow in Figure 7 for CPNiAl-1, CPNiAl-2, and NiAl-Si were used. ${ }^{[33]}$ This method yields an activation energy ranging from 66 to 75 $\mathrm{kJ} / \mathrm{mol}$.

Finally, the activation energy for serrated flow can be determined from the stress-drop technique. ${ }^{[33.34]}$ For this method, the magnitude of the stress drop $\Delta \sigma$ accompanying serrated flow is measured at a given strain for a range of $\dot{\varepsilon}$ and $T$ and plotted as indicated in Figure 8(a). A constant value for $\Delta \sigma$ is then selected from which the $\dot{\varepsilon}$ corresponding to this $\Delta \sigma$ is determined for each temperature. The resulting $\dot{\varepsilon}$ is then plotted as a function of $1 / T$ and $Q$ is determined from its slope (i.e., $Q=-(\ln \hat{E} R T))$. Detailed descriptions of this method are provided in References 33 and 34. Figures 8(a) through (c) show the $\Delta \sigma v s \dot{\varepsilon}$ and $\dot{\varepsilon}$ vs $1 / T$ plots for CPNiAl-1, CPNiAl-2, and NiAl-Si. Activation energies in the range 86 to $102 \mathrm{~kJ} / \mathrm{mol}$ were ascertained for all three alloys by this technique.

Activation energies determined by all three methods are summarized in Table II and are in very good agreement with the activation energies determined for SSA in polycrystalline $\mathrm{NiAl}(70 \text { to } 76 \mathrm{~kJ} / \mathrm{mol})^{(15.19 .20)}$ and are only marginally less than the activation energy for serrated flow in single-crystal $\mathrm{NiAl}$ reported by Brzeski and co-workers (115 and $134 \mathrm{~kJ} / \mathrm{mol})$ [5.16] $^{\text {(1) }}$

\section{Optical Microscopy and TEM Observations of Deformed Samples}

Representative TEM bright-field images of the dislocation structures after deformation at room temperature, in the DSA regime, and above the DSA regime for the various alloys are shown in Figures 9 through 13. Diffraction contrast analysis revealed that deformation occurred by the motion of $(001)$-type dislocations at all temperatures. Figure 9 shows the deformation microstructures in CPNiAl-2 samples deformed at room temperature to two different strain levels. In agreement with previous observations, ${ }^{[15,35-38]}$ the



(a)



(b)
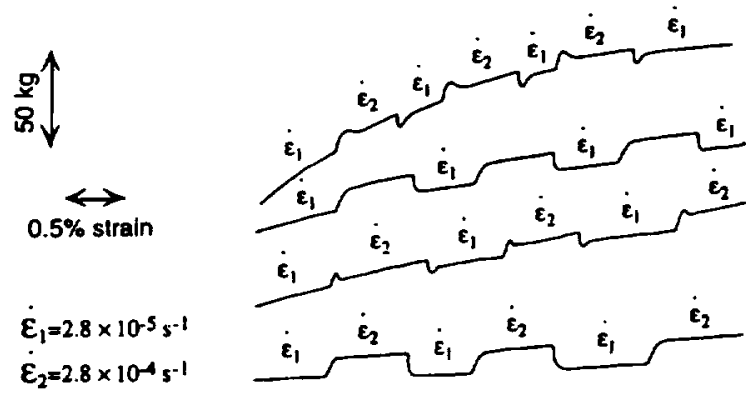

$300 \mathrm{~K}$

$575 \mathrm{~K}$

$670 \mathrm{~K}$

(c)

Fig. 5-The effect of temperature on the shape of the flow curves of HPNiAl and UF-NiAll deformed at $\dot{\varepsilon}=2.8 \times 10^{-9} \mathrm{~s}^{-1}$. (a) and (b) HPNiAl following unixial deformation and strain-rate change experiments (c) UF-NiAll following strain rate change experiments near 5 pct plastic strain. The arrows in (a) denote the location of the $0.2 \mathrm{pct}$ offset yield stress.

microstructure consists of jogged and curved dislocation segments and dislocation debris in the form of elongated 


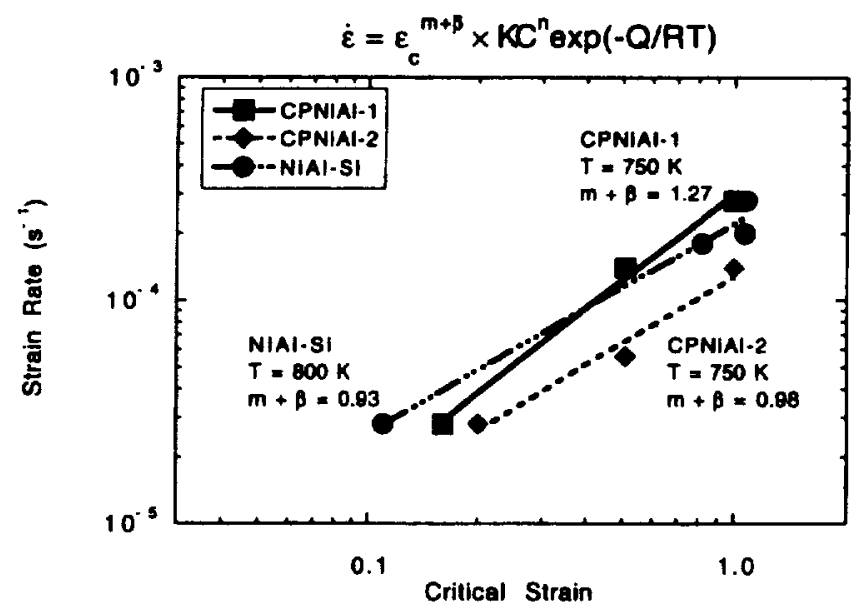

(a)



(b)

Fig. 6-The influence of $\dot{\varepsilon}$ and $T$ on the critical strain for the onset of serrated flow, $\varepsilon_{s}$ for CPNiAl-1, CPNiAl-2, and NiAl-Si: (a) $\ln \dot{\varepsilon}$ vs $\ln \varepsilon_{c}$ and $(b)$ in $\varepsilon_{c}$ is $1 / T$

loops. At high strains (Figure 9(b)), the dislocations arrange themselves into cellular networks containing a low volume fraction of intercellular dislocations or debris. Such structures are attributed to the easy cross-slip of screw dislocations during room-temperature deformation..$^{[35-38]}$

Figure 10(a) shows the deformation microstructure of a CPNiAl-1 sample deformed at $700 \mathrm{~K}$ in the DSA regime. The microstructure of CPNiAl-1 consists of poorly defined cells or the beginning of a vein structure with the densest cell walls oriented parallel to the $\langle 110\rangle$ crystallographic direction. Coincident with this deformation structure was a relatively high density of dislocations within the cell walls Figure 10(a). Cell walls in non- $\langle 110\rangle$ directions were particularly poorly defined indicating some sort of localized or planar deformation process in this temperature regime. This structure is reminiscent of the ones developed during lowcycle fatigue testing of ferritic $\mathrm{Fe}-24 \mathrm{Cr}-4 \mathrm{Al}{ }^{[39]}$ and polycrystalline $\mathrm{NiAl}$ in the DSA regime. ${ }^{[40]}$ Similar deformation microstructures were observed in $\langle 110\rangle$-oriented CPNiAl-2 and $\mathrm{NiAl}-\mathrm{Si}$. An example of the structure that evolved in the NiAl-Si alloy following deformation at its SRS minimum is shown in Figure 10(b). In this case, the cell walls oriented parallel to the $(100\rangle$ direction. Similar observations



(a)

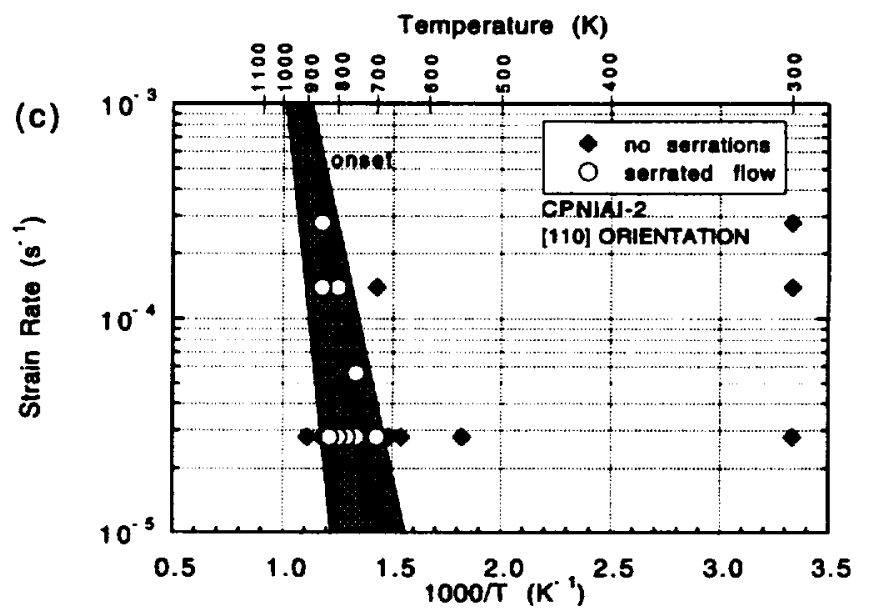

(b)

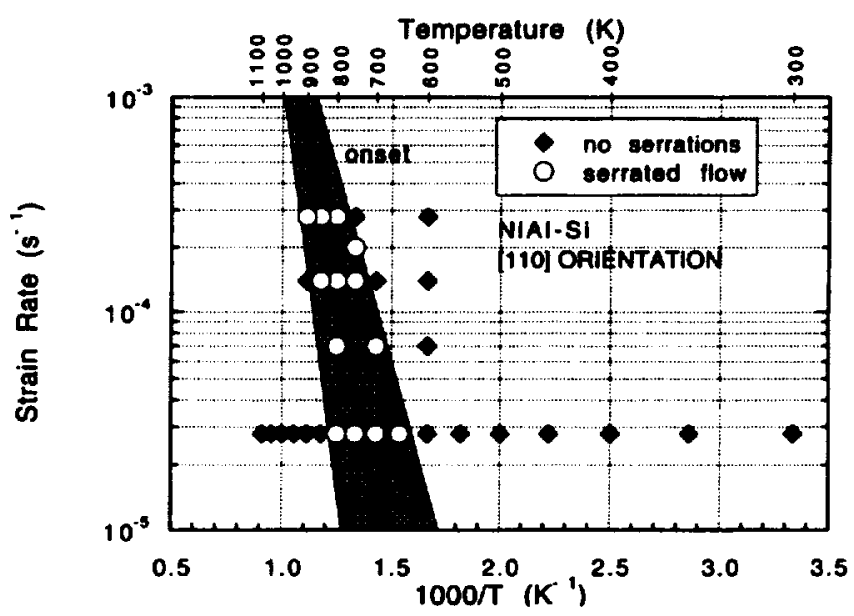

(c)

Fig. 7-Plots of $\ln \dot{\varepsilon}$ vs 1/T for CPNiAl-1, CPNiAl-2, and NiAl-Si illustrating the $T-\dot{\varepsilon}$ regimes for the occurrence of serrated flow. (a) CPNiAl-1, (b) CPNiAl-2, and (c) NiAl-Si.

have been reported previously for $(110\rangle$-oriented conventional purity $\mathrm{NiAl}$ single crystals. ${ }^{(41,42,43]}$

Figure 11 shows the deformation substructure observed in CPNiAl-1 following deformation at $1000 \mathrm{~K}$. This structure was characterized by a much lower dislocation density 




(a)

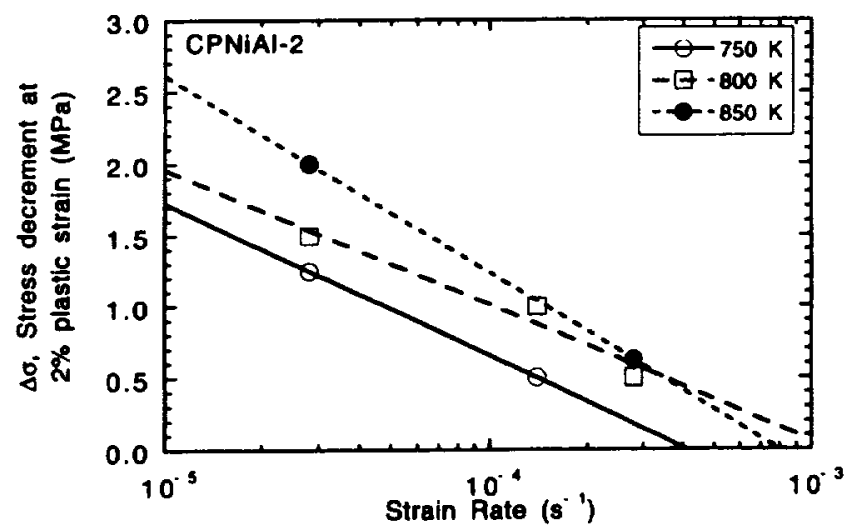

(c)

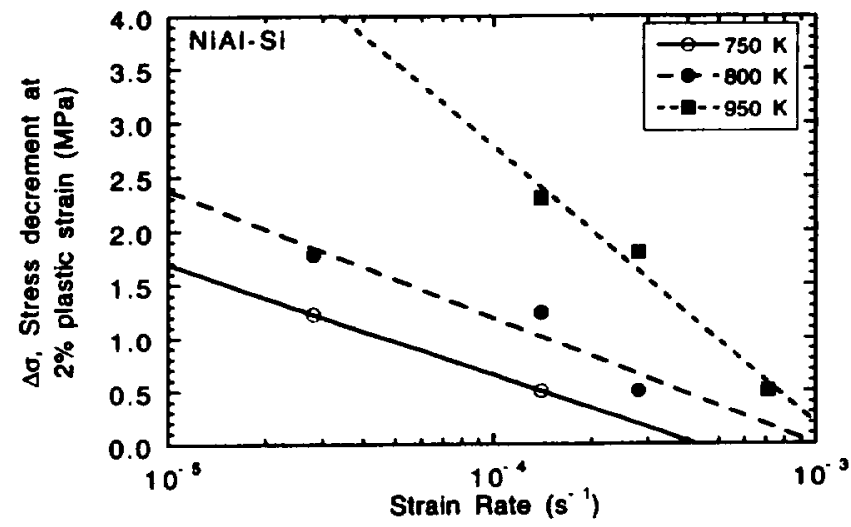

(e)

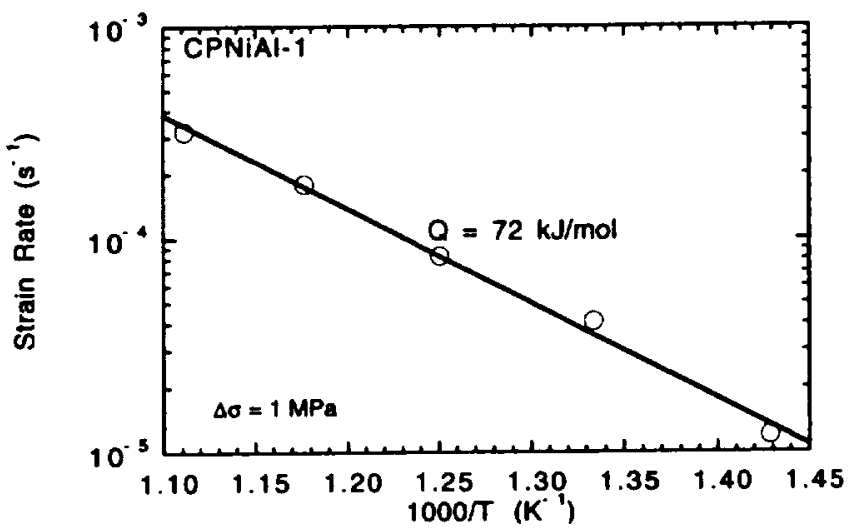

(b)

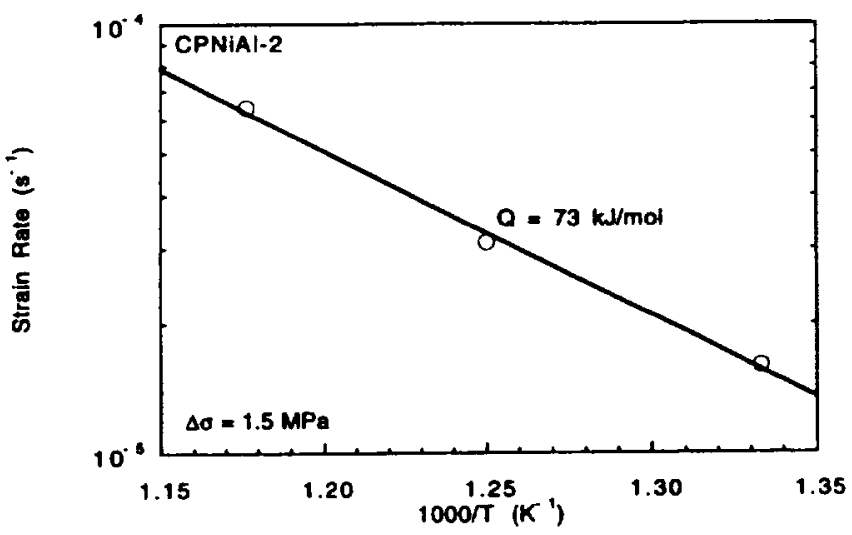

(d)

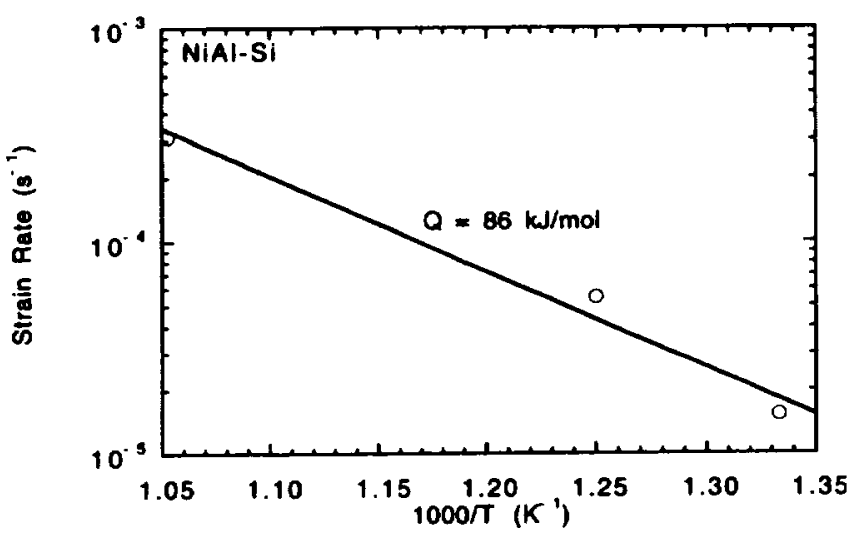

(f)

Fig. 8-Plots of the stress drop at 2 pct plastic strain vs $\dot{\varepsilon}$ at constant $T$ and $\dot{\varepsilon}$ vs $1 / T$ for CPNiAl-I, CPNiAl-2, and NiAl-Si illustrating use of the stress drop method for determining activation energy. ${ }^{\mid 3 !}(a)$ and $(b)$ CPNiAl-1; (c) and $(d) \mathrm{CPNiAl}-2$; and $(e)$ and $(f) \mathrm{NiAl}-\mathrm{Si}$.

Table II. Summary of the Activation Energies for Serrated Flow Evaluated Using Different Methods for Conventional Purity and Si-Doped NiAl Single Crystals

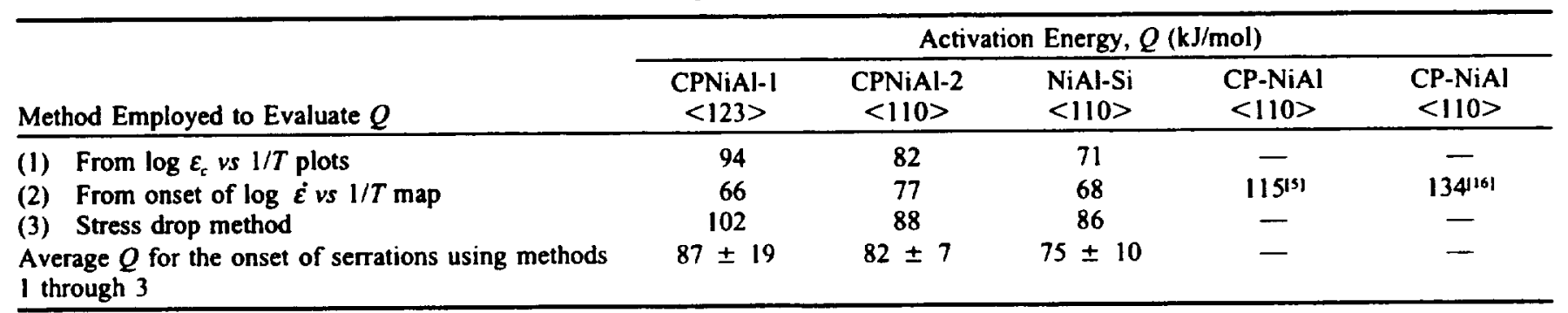




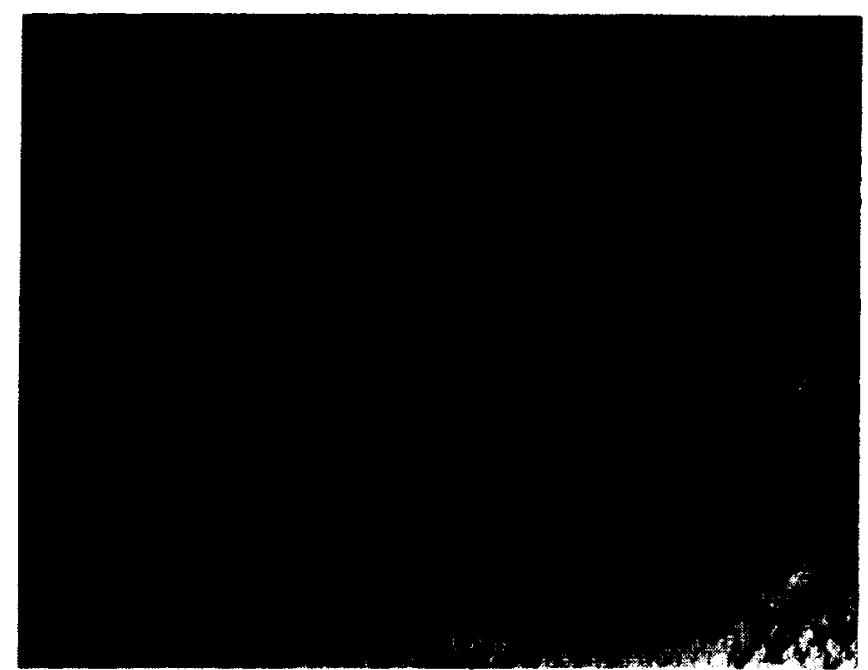

(a)

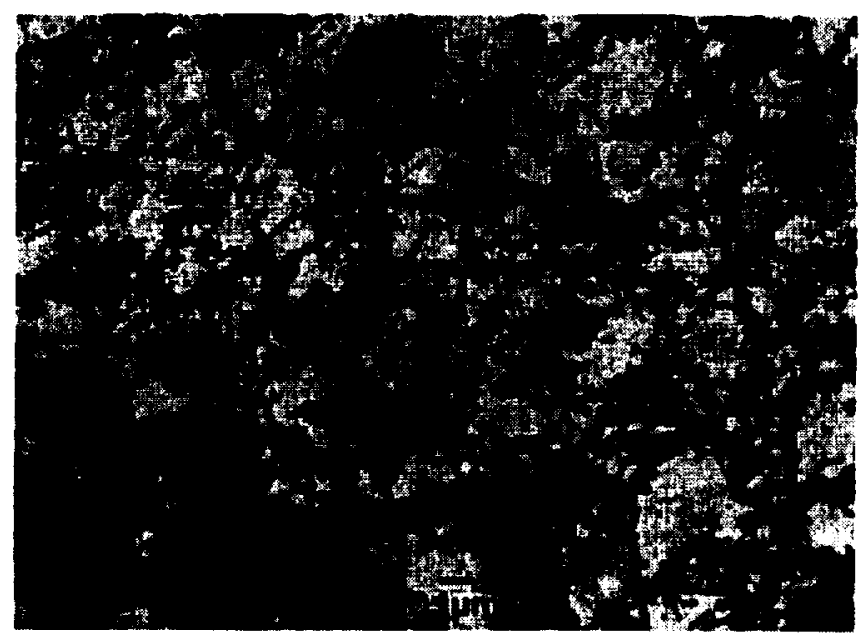

(b)

Fig. 9-Room-temperature deformation structure observed in CPNiAl-2: (a) after $\sim 0.2$ pct plastic deformation and $(b)$ after $\sim 2$ pct plastic deformation.

than that observed at $300 \mathrm{~K}$ or at the SRS minimum and the general lack of a cell structure. This is attributed to the greater relaxation and recovery effects which become important at this temperature.

In NiAl-Mo following deformation at the SRS minimum (Figure 12), structures consisting of poorly defined cells and dislocation tangles were observed. However, the vein structures observed in CPNiAl-1 were not as evident, though the densest cell walls were again those aligned along $\langle 110\rangle$. In addition, a lower density of intercellular debris and dislocations was observed even after levels of deformation equivalent to those in CPNiAl-1. In HP-NiAl (Figure 13(a)), cellular structures characterized by large, loosely packed cell walls with very little intercellular debris were observed, indicating a much greater ease of cross-slip in this alloy compared to either CPNiAl-1, NiAl-Si, or NiAl-Mo at comparable intermediate temperatures. On occasion, single slip bands were observed propagating across the sample (Figure 13(b)), indicating some localized slip processes but not to the same degree as in the other alloys.

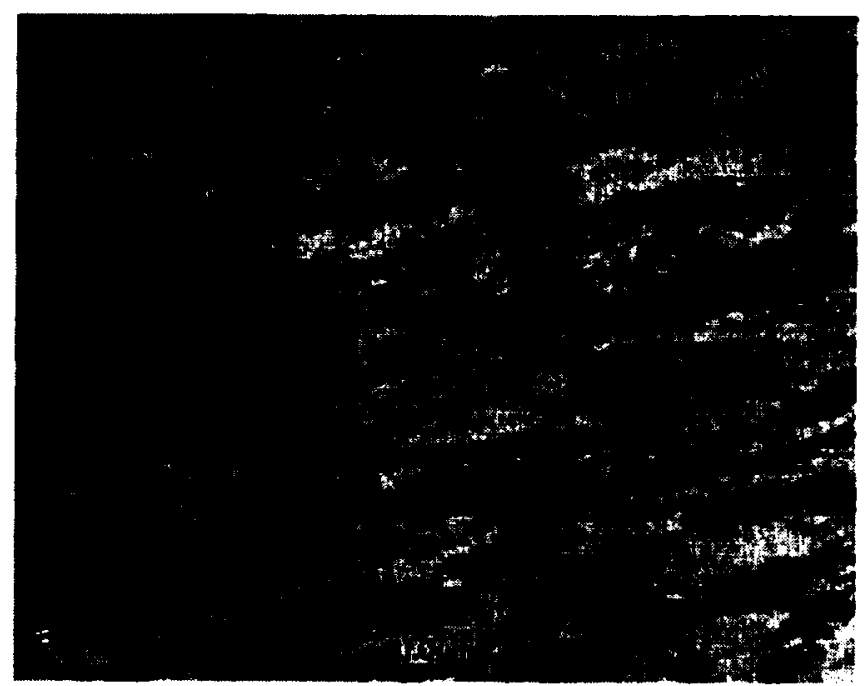

(a)



(b)

Fig. 10-Deformation structures observed in CPNiAl-l and NiAl-Si after $\sim 17$ pct plastic deformation. (a) CPNiAl-1 at $700 \mathrm{~K}$ and (b) NiAl-Si at $700 \mathrm{~K}$.

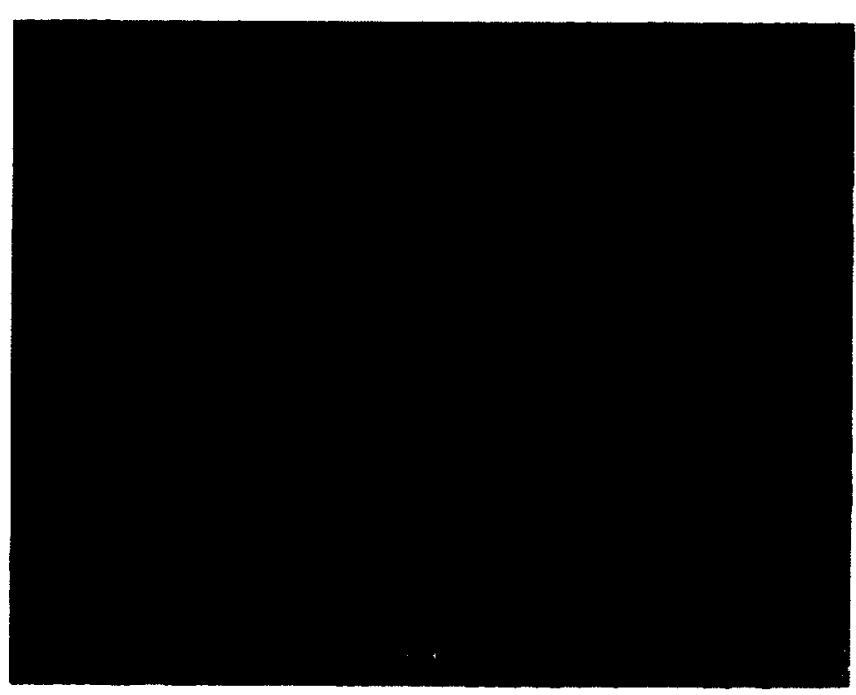

Fig. 11-Dislocation morphology observed in CPNiAl-1 after 11 pet deformation at $1000 \mathrm{~K}$. 


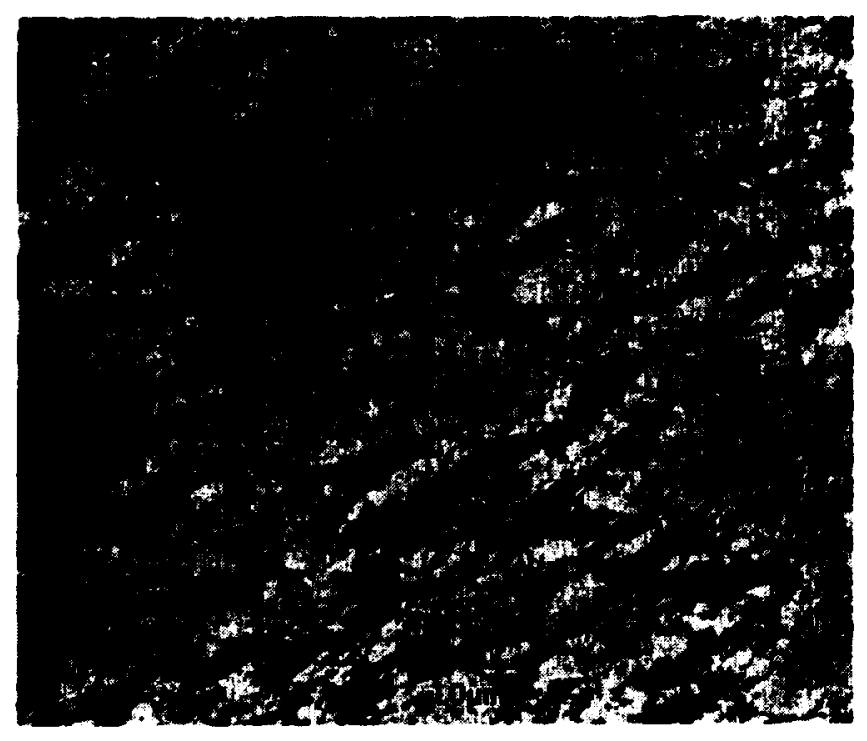

Fig. 12-Deformation structure observed in NiAl-Mo after 9 pct plastic deformation at $700 \mathrm{~K}$

Additional evidence for planar slip processes in the DSA regime was revealed in the optical morphology of slip traces on the various specimen surfaces (Figures 14 and 15). Slip bands were observed throughout the gage of all specimens and at all test temperatures similar to the behavior shown in Figure 14 for CPNiAl-1. In CPNiAl-1, for example, indistinct slip traces were observed on specimens tested at room temperature (Figure 14(a)). However, as the test temperature was increased towards the SRS minimum, the slip traces became more distinct and more coarsely spaced (Figures 14(b) through (d)). At temperatures well above the SRS minimum, more indistinct, finely spaced, and diffuse traces were again observed (Figure 14(e)). In the $\langle 123\rangle$-oriented specimens, single slip traces were predominantly observed, whereas in (110)-oriented specimens intersecting slip traces from multiple slip systems were common. An example of this is illustrated in Figure 15. In agreement with prior studies, ${ }^{[18,35,44]}$ slip trace analysis confirmed that slip occurred on $\{110\}$ or $\{100\}$ planes with the actual slip plane being dependent upon specimen orientation. In $\langle 110\rangle$-oriented specimens, traces consistent with $\{100\}$ slip planes were typically observed, while traces consistent with $\{110\}$ slip planes were observed in $\langle 123\rangle$-oriented specimens. The DSA and serrated flow behavior were observed to the same extent regardless of the operative slip plane.

\section{DISCUSSION}

\section{A. Manifestations of Dynamic Strain Aging}

The temperature-dependent properties (i.e., CRSS/E, SRS, and $\theta / E$ ) and the deformation substructures exhibit several features that can be associated with the occurrence of strain aging. First, the temperature dependencies of the CRSS $/ E$ and $\theta / E$ should decrease with increasing temperature. In the cases of the CPNiAl-1, CPNiAl-2, UF-NiAll, $\mathrm{NiAl}-\mathrm{Mo}$, and $\mathrm{NiAl}-\mathrm{Si}$ alloys, however, anomalous regions in the form of local peaks or plateaus were observed in the

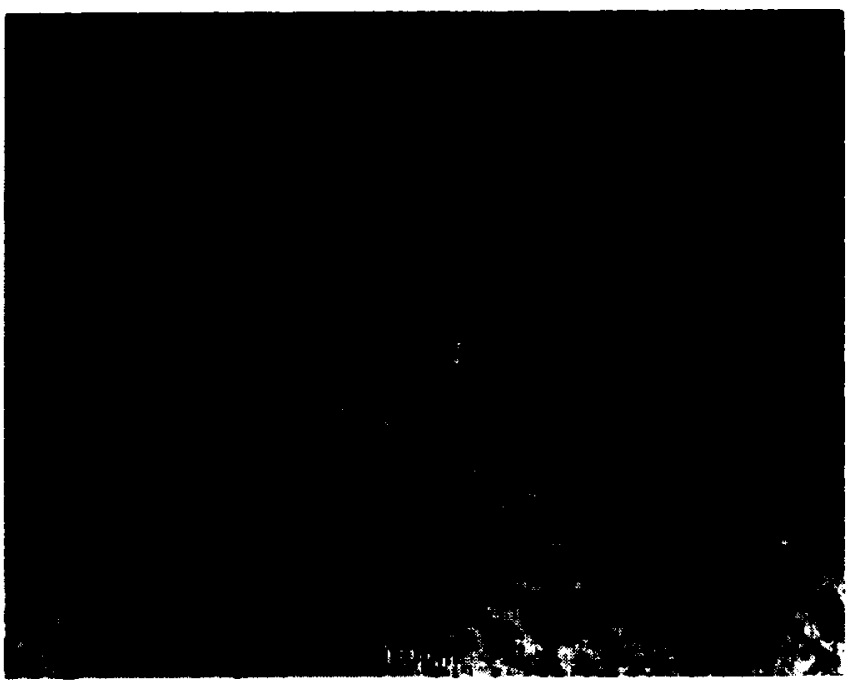

(a)

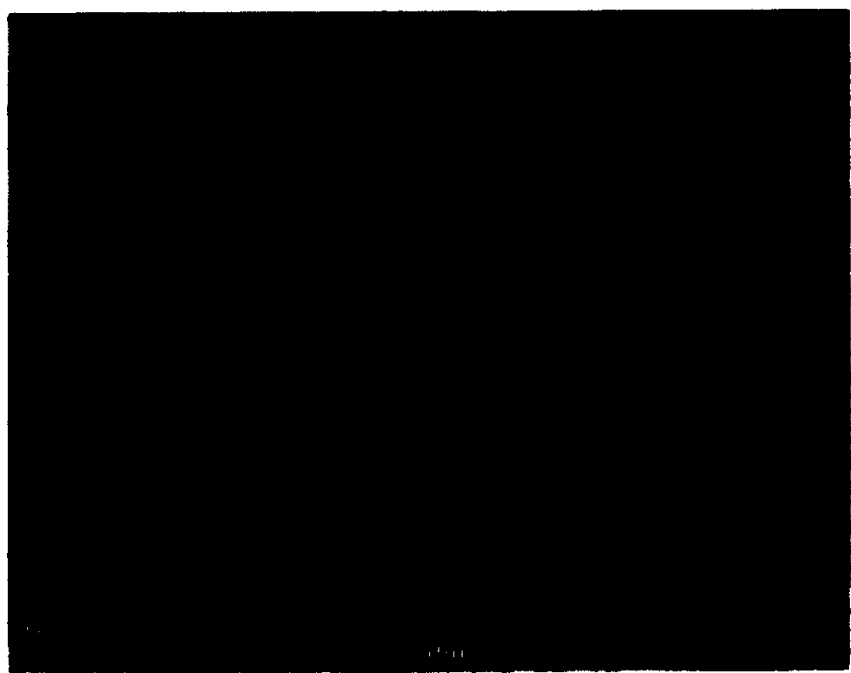

(b)

Fig. 13-Deformation structure observed in HP-NiAl after 9 pet plastic deformation at $725 \mathrm{~K}$. (a) Cellular morphology typical of most samples and $(b)$ a single deformation band observed in one of the foils.

temperature range of 650 to $1000 \mathrm{~K}$. No similar features were observed for $\mathrm{HP}-\mathrm{NiAl}$.

Second, the temperature dependence of the SRS exhibited distinct minimums for all six alloys in low and intermediate temperature ranges, with SRS actually becoming negative for CPNiAl-1, CPNiAl-2, and NiAl-Si in the intermediate temperature range. Coincident with this region of negative SRS was the observation of serrated flow during mechanical testing, which directly supports the premise that DSA occurs in this intermediate temperature range in NiAl. In HP-NiAl, NiAl-Mo, and in UF-NiAl1, SRS always remained positive and serrated flow was not observed. However, flow-stress transients on changes in strain rate in the form of sharp upper yield points were consistently observed during testing near the SRS minimum in UF-NiAll and NiAl-Mo, which are again indicative of DSA. No flowstress transients were observed at intermediate temperatures during the testing of HP-NiAl. Additionally, SRS minima were observed to occur at lower temperatures than the CRSS/ $E$ or $\theta / E$ maxima. Such observations support the no- 




(a)



(b)

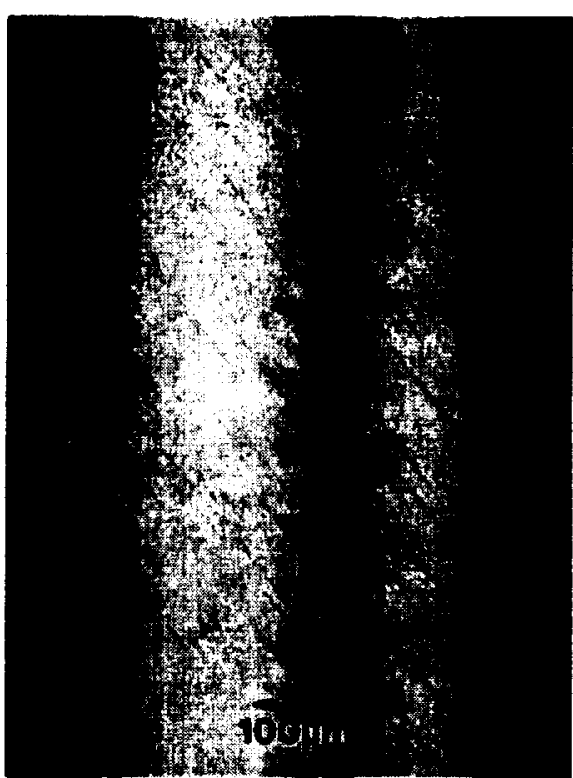

(c)

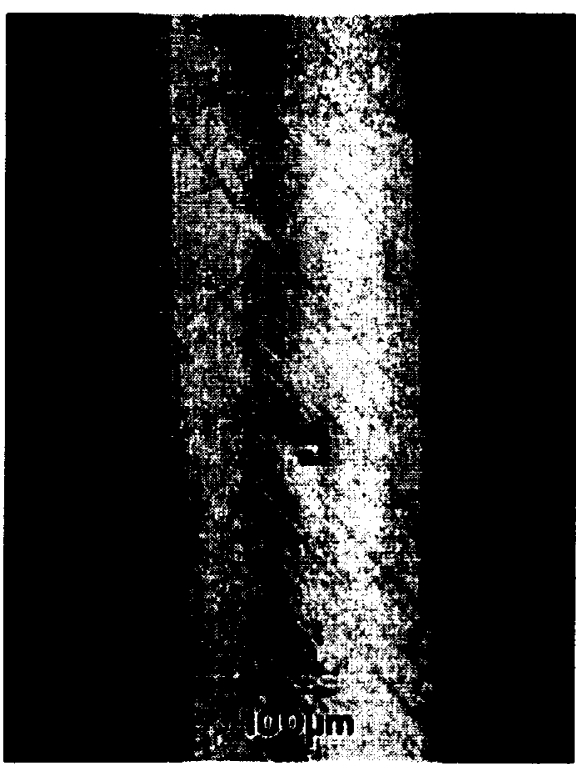

(d)

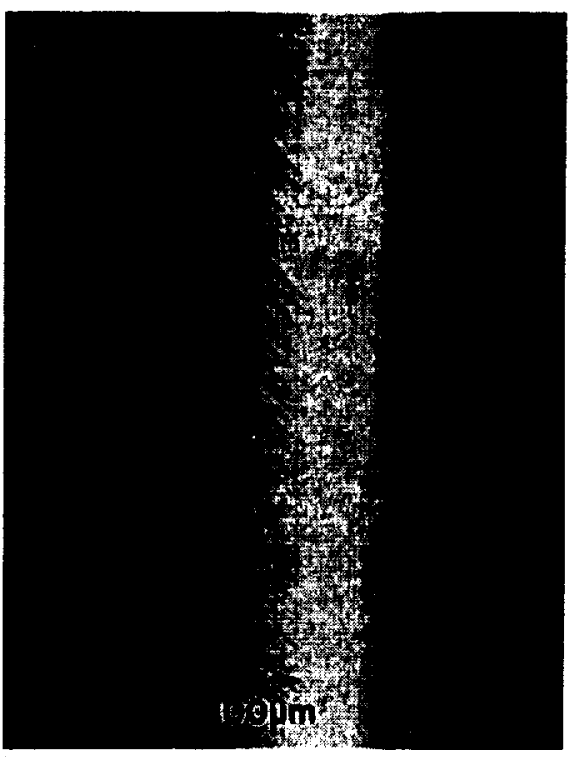

(e)

Fig. 14-Optical micrographs of the gage section CPNiAl-1 samples deformed in tension over the temperature range 300 to $1000 \mathrm{~K}$. (a) $300 \mathrm{~K}$, (b) 500 $\mathrm{K},(c) 600 \mathrm{~K},(d) 750 \mathrm{~K}$, and (e) $1000 \mathrm{~K}$. Note the presence of coarse slip traces at 600 and $750 \mathrm{~K}$.

tion of a DSA effect. ${ }^{[30.31 .45]}$ Classical theory ${ }^{[31.45]}$ indicates that during the occurrence of DSA, dislocation motion is characterized by a waiting time $t_{w}$ during which dislocations are temporarily arrested at obstacles in the slip path. During this waiting time the dislocations can be further pinned by diffusing solutes. This causes the obstacles to dislocation motion to become stronger with increased waiting time and results in an enhanced resistance to plastic deformation. The SRS is said to become minimum when the time required to pin a dislocation $t_{a}$ becomes equal to the waiting time. Thus, when $t_{w}$ is fixed by fixing the strain rate, strengthening will become maximum when the temperature becomes high enough that $t_{a}<t_{w}$, i.e., maximum strengthening will occur at higher temperatures than the SRS minimum.

Third, distinctively coarse slip traces were observed on the surfaces of specimens deformed in the intermediate temperature range, while finer traces persisted outside of this temperature regime. Slip-trace analysis confirmed that these traces were preferentially oriented along specific crystallographic directions based upon the initial orientation of the crystal. More detailed analysis of the dislocation substructures formed during deformation at temperatures both below and above the regime where serrated flow occurs were characterized by cell structures and dense tangles. These structures are characteristic of intense cross-slip at low temperatures or dislocation climb at high temperatures. In contrast, the substructure formed in the DSA regime was typified by a coarse dislocation vein structure. An important additional feature in samples exhibiting serrated flow is that the regions between the dislocation walls often contain a rather uniform dislocation distribution. It is proposed that 




Fig. 15-Optical micrograph of NiAl-Si deformed in compression at 800 $\mathrm{K}$ illustrating interesecting $\langle 100\rangle$ slip traces.

these interwall dislocations result from solute locking of slow-moving dislocations between slip bands. Inhomogeneous deformation occurs as a result of differential movement of dislocations within and between the dislocation walls.

Based on the results described here, it is possible to attribute the anomalous mechanical behaviors observed in this study to DSA or the migration of solutes to mobile dislocations during deformation. Additional confirmation of this phenomenon is provided by SSA and DSA studies performed on soft-oriented single crystals ${ }^{[3.6 .9 .16-18]}$ and on polycrystalline $\mathrm{NiAl},{ }^{[14.13 .19 .20]}$ wherein serrated yielding, flow stress transients, and a $t^{2 / 3}$ time dependence of the yield point return have been observed in conventional purity and in carbon doped $\mathrm{NiAl}$ alloys.

\section{B. The Diffusing Species}

It is possible to ascertain the species responsible for strain aging by examining the data generated in this study. In Section III, it was noted that the values for the exponent $(m+\beta)$ were within the range 0.9 to 1.3 . Typically when $(m+\beta)$ is between 2 and 3 , the specie resulting in serrated yielding is a substitutional element, whereas when $(m+\beta)$ is in the range 0.5 and 1 , an interstitial specie is responsible. ${ }^{[30]}$ Additional inferences can be made by comparing the calculated activation energies for strain aging with the limited diffusion data available for $\mathrm{NiAl}$. Independent of composition, the average activation energy for the diffusion of substitutional elements in NiAl is in the neighborhood of $225 \pm 39 \mathrm{~kJ} / \mathrm{mol}$, which is somewhat inconsistent with the activation energy for the formation and migration of vacancies in NiAl which is closer to $300 \mathrm{~kJ} / \mathrm{mol} .{ }^{\left[{ }^{13]}\right.}$ Nonetheless, as indicated Section III, the experimentally determined activation energies for strain aging lie within the range $\mathbf{7 0}$ to $100 \mathrm{~kJ} / \mathrm{mol}$, which are far lower than those required to move substitutional solutes or point defects and which are within the range for the diffusion of interstitial solutes in bcc metals (Table III).

The specific interstitial species responsible for DSA can be identified by comparison of the deformation behavior for the six single-crystal alloys vs their composition and the
Table III. Activation Energies for Diffusion of Solutes and Point Defects in Metals and Alloys (kJ/mole)

\begin{tabular}{|c|c|c|c|c|c|c|}
\hline \multirow[b]{2}{*}{$\begin{array}{l}\text { Alloy/ } \\
\text { Metal }\end{array}$} & \multicolumn{6}{|c|}{ Element/Point Defect* } \\
\hline & $\mathrm{H}$ & $\mathrm{C}$ & $\mathrm{N}$ & $\mathrm{O}$ & Vacancy & $\begin{array}{c}\text { subst. } \\
\text { solutes }\end{array}$ \\
\hline V & - & 114 & 143 & 121 & - & - \\
\hline $\mathrm{Nb}$ & - & 138 & 146 & 113 & 一 & - \\
\hline $\mathrm{Ta}$ & $25^{146}$ & 161 & 158 & 107 & 一 & - \\
\hline $\mathrm{Cr}$ & - & - & 102 & - & 一 & 一 \\
\hline $\mathrm{Fe}$ & $\begin{array}{c}8.4 \\
12 \text { to } 13\end{array}$ & 80 to 84 & 73 to 78 & - & - & - \\
\hline $\mathbf{w}$ & - & 169 & - & - & 一 & - \\
\hline $\mathrm{NiAl}$ & - & - & - & - & $-300^{131}$ & $-225^{[13]}$ \\
\hline
\end{tabular}

Data taken from Ref. [47] unless otherwise noted.

results from previous studies. ${ }^{14,15,19.20]}$ In these previous studies, $O$ and $N$ were ruled out as the cause of SSA effects in polycrystalline alloys. In this study, serrated flow was observed in CPNiAl-1, CPNiAl-2, and NiAl-Si, but, not in HP-NiAl, UF-NiAll, or NiAl-Mo. In HP-NiAl, the C and Si concentrations were much lower than those observed in CPNiAl-1, CPNiAl-2, or NiAl-Si (i.e., 76 at. ppm C vs $>150$ at. ppm $\mathrm{C}$ and 500 at. ppm Si $v s>1500$ at. ppm Si), which suggests that the lack of serrated flow in HP-NiAl is related to reductions in the $\mathrm{C}$ and/or Si contents. That both elements are important for the observation of DSA is supported by the results of Weaver ${ }^{[15]}$ and the results of Hack and co-workers ${ }^{[5.69 .16 .17]}$ and Brzeski. ${ }^{[18]}$ Weaver showed that yield-point formation is enhanced and that serrated flow is observed in conventional-purity polycrystalline alloys containing $>1500$ at. ppm Si in addition to normal levels of C (approximately 150 at. ppm). Similarly, Hack and coworkers and Brzeski observed dramatic increases in fracture toughness following intermediate temperature annealing and serrated flow in soft-oriented single crystals containing between 145 and 470 at. ppm $C$ and between 1300 and 2500 at. ppm Si. When $C$ is maintained at levels comparable to the conventional-purity single-crystal alloys but $\mathrm{Si}$ is reduced to less than 100 at. ppm, as in the case of UF$\mathrm{NiAl1}$, serrated flow is not observed but yield stress transients upon an increase in strain rate and a yield-stress plateau are still observed between 600 and $900 \mathrm{~K}$. This indicates that $C$ still causes some strain-aging behaviors but that Si somehow enhances the effect. Finally, in NiAl-Mo, the bulk Si levels were nearly equivalent to those in $\mathrm{NiAl}$ Si (i.e., 0.23 vs 0.29 at. pct $\mathrm{Si}$ ) while the bulk interstitial levels were higher than those observed in CPNiAl-1, CPNiAl-2, and NiAl-Si, the three alloys that exhibited serrated flow. However, no serrated flow was observed in NiAl-Mo. The microstructural analysis presented in this article showed that this alloy contains a distribution of coarse $\mathrm{Mo}_{2} \mathrm{C}$ precipitates and suggests that the lack of serrated flow in NiAl-Mo is due to the gettering of $\mathrm{C}$ from the NiAl matrix. Were $\mathrm{Si}$ the cause for the serrated yielding instead of $C$, it is expected that serrated yielding would also be observed in NiAl-Mo since it contains nearly as much Si as the NiAl-Si alloy. In addition, if $\mathrm{C}$ alone were the cause, then it is expected that serrated yielding would be observed in UF-NiAll, which contains more $\mathrm{C}$ than CPNiAl-2 but only 69 at. ppm Si. Therefore, these results strongly suggest that the serrated yielding in $\mathrm{NiAl}$ is a result of interactions 
between dislocations and solute atoms, namely $\mathrm{C}$ and $\mathrm{Si}$, but that $\mathrm{C}$ is the main cause for the manifestations of DSA observed in the $\mathrm{NiAl}$ single crystals investigated in this study.

In Section III, it was noted that two SRS minima were observed for each alloy: one at low temperatures and the other at intermediate temperatures. Though it is tempting to attribute the low and intermediate temperature minima to $\mathrm{C}$ and $\mathrm{Si}$, respectively, a conclusive statement cannot be made at this time. Were the low-temperature SRS minima the result of $\mathrm{C}$, it is expected that the conventional-purity and Si-doped alloys also would exhibit flow-stress transients or serrated flow at low temperatures. Prior investigations have illustrated, both experimentally and theoretically, that two SRS minima due to Snoek ordering and Cottrell atmosphere formation are often observed in bcc and in bcc-like (e.g., B2) systems when DSA is caused by an interstitial specie ${ }^{[48-53]}$ and other systems where interstitialvacancy clusters are known to cause DSA. ${ }^{[34]}$ Thus, it is possible that both minima are caused by the same specie, however, more complete investigations of the low temperature regime are warranted before a definitive conclusion can be formulated.

Furthermore, while it is impossible to devise a definitive mechanism by which $\mathrm{Si}$ and $\mathrm{C}$ can synergistically cause serrated flow, it is possible to speculate. First, it is possible that $\mathrm{Si}$ simply modifies the activity coefficient of $\mathrm{C}$ in NiAl. It has been observed in austenitic Fe-Mn-C alloys ${ }^{[55.56]}$ that the addition of aluminum raised the activation energy for the onset of serrated flow by reducing the carbon activity, and thus its diffusivity, in these alloys. The opposite effect could occur in the case of $\mathrm{NiAl}$, where $\mathrm{Si}$ increases the activity and diffusivity of $\mathrm{C}$ in $\mathrm{NiAl}$ and thus decreases the activation energy for the onset of serrated flow. The results collected in this study indicate that the activation energies for the onset of serrated flow in CPNiAl-1 (0.17 at. pct Si), CPNiAl-2 (0.15 at. pet Si), and in NiAl-Si (0.25 at. pct Si) are similar. Unfortunately, no activation energy could be calculated for $\mathrm{NiAl}$ containing lower $\mathrm{Si}$ concentrations, since serrated flow was not observed.

Second, DSA could be the result of an interaction solid solution hardening (ISSH) effect as described in References 57 through 61 . This process is attributed to the strengthening that arises from the simultaneous presence in solid solution of substitutional and interstitial atoms that exhibit an affinity for each other. The exact reasons for ISSH are unknown but depend upon how these solute atoms interact with each other and with moving dislocations. ${ }^{\text {[39] }}$ For example, when interstitials bind strongly to dislocations, strain-aging effects are caused by the reduced mobility of the dislocations which must now drag interstitial atmospheres along with them. However, if interstitials also bind strongly with substitutional solutes, strain aging can be extended to higher temperatures due to the reduced mobility of the interstitial caused by interaction with the substitutional solute (i.e., dislocations must now drag interstitialsubstitutional clusters rather than individual interstitials). Diffusion-couple studies between $\mathrm{NiAl}, \mathrm{Ni}_{3} \mathrm{Al}$, and $\mathrm{SiC}^{\text {[62.63] }}$ have suggested that $\mathrm{Si}$ may diffuse as fast as or faster than $\mathrm{C}$ in $\mathrm{NiAl}$ and may result in the formation of complex $\mathrm{Ni}$ Al-Si-C phases. This suggests that some clustering of $\mathrm{C}$ with $\mathrm{Si}, \mathrm{Ni}$, and $\mathrm{Al}$ may occur resulting in an expansion of the DSA regime and stronger pinning.

A third possibility is that substitution of a smaller $\mathrm{Si}$ atom can result in an increased tetragonal distortion in the $\mathrm{NiAl}$ lattice. Recent theoretical results suggest that $\mathrm{Si}$ will only occupy Al lattice positions, ${ }^{[6-1]}$ whereas other substitutional elements such as Fe or Ga will tend to occupy the site of the stoichiometrically deficient host element. ${ }^{\text {[64.65] }}$ Assuming that $\mathrm{C}$ atoms occupy octahedral sites, it is theorized that the substitution of smaller $\mathrm{Si}$ atoms for $\mathrm{Al}$ will result not only in a reduction in the size of the octahedral interstices but also into more localized distortions of the lattice. Similarly, in the cases of Fe or $\mathrm{Ga}$, which occupy the stoichiometrically deficient host element sites, the overall distortions in the lattice will be minimized because the tetragonal distortions created by interstitial atoms can be partially accomodated, resulting in reduced strain-aging effects. Recently, serrated yielding has been reported to occur over a smaller temperature range in both Fe-doped and in Ga-doped single-crystal alloys, ${ }^{106]}$ which suggests that there might be some validity to this potential mechanism though more work is needed.

Determination of the actual mechanism behind the synergistic effect of $\mathrm{C}$ plus $\mathrm{Si}$ on DSA in NiAl will require further study. In light of the fact that $\mathrm{Si}$ is frequently present in conventional-purity $\mathrm{NiAl}$ single crystals grown by the Bridgman method due to contamination from alumina-silicate shell molds, this topic deserves additional attention.

\section{SUMMARY AND CONCLUSIONS}

Five of the six alloys examined in the present study exhibit yield stress and work-hardening plateaus or small peaks in the temperature range 650 to $1000 \mathrm{~K}$, indicative of DSA. In HP-NiAl, anomalous behavior was not evident.

Pronounced regions of negative SRS have been observed in conventional-purity (CPNiAl-1 and CPNiAl-2) and Sidoped (NiAl-Si) alloys in the temperature range 600 to 800 $K$. Coincident with this temperature regime was the occurrence of serrated flow (i.e., the PLC effect).

In the temperature range where serrated flow occurs, the dislocation distribution consists mainly of thick dislocation walls or the beginning of a vein structure indicating localized slip. In HP-NiAl and NiAl-Mo, the dislocations maintain cellular networks indicating more abundant and, therefore, easier cross slip. At temperatures above or below the regime of serrated flow, well-developed cell structures dominate for all alloys.

Average activation energies for serrated flow have been calculated using three methods: $84 \pm 10 \mathrm{~kJ} / \mathrm{mol}\left(\varepsilon_{\mathrm{c}} v s T\right)$, $73 \pm 1 \mathrm{~kJ} / \mathrm{mol}$ (stress-drop method), and $78 \pm 7 \mathrm{~kJ} / \mathrm{mol}$ (Arrhenius method). All values are reasonable order of magnitude estimates for interstitial diffusion in bcc lattices and agree with prior observations in polycrystalline $\mathrm{NiAl}$ and with Hack and co-workers. ${ }^{[5,6,9,16,17]}$

Overall, these results suggest that a combination of interstitial and substitutional solutes, namely, $\mathrm{C}$ and $\mathrm{Si}$, cause serrated flow in soft-oriented NiAl. Small additions of Mo to $\mathrm{NiAl}$ caused a dramatic increase in yield stress but eliminated the serrated yielding. This latter effect is attributed to the gettering of $\mathrm{C}$ by Mo. 


\section{ACKNOWLEDGMENTS}

Sincere gratitude is expressed to Drs. R. Darolia, B.F. Oliver, and V.I. Levit for enlightening technical discussions and for providing the single-crystal alloys used in this study; to A.J. Duncan for his assistance with the low-temperature mechanical testing; and also to P.O. Dickerson for her assistance with the SEM/EDS. MLW and MJK express their appreciation for the financial and technical support of the NASA-Lewis Research Center under Grant No. NGT32958.

\section{REFERENCES}

1. R.W. Margevicius and J.J. Lewandowski: Scripta Metall. Mater., 1991, vol. 25, pp. 2017-22.

2. R.W. Margevicius, J.J. Lewandowski, I.E. Locci, and R.D. Noebe: Scripta Metall. Mater., 1993, vol. 29, pp. 1309-12.

3. R.W. Margevicius and J.J. Lewandowski: Acta Metall. Mater., 1993 vol. 41, pp. 485-96.

4. R.W. Margevicius, J.J. Lewandowski, and I.E. Locci: in Structural Intermetallics, R. Darolia, J.J. Lewandowski, C.T. Liu, P.L. Martin, D.B. Miracle, and M.V. Nathal, eds., TMS, Warrendale, PA, 1993, pp. $577-84$.

5. J.E. Hack, J.M. Brzeski, and R. Darolia: Mater. Sci. Eng., 1995, vols A192-A. 193, pp. 268-76.

6. J.E. Hack, J.M. Brzeski, R. Darolia, and R.D. Field: in High Temperafure Ordered Intermetallics V, I. Baker, R. Darolia, J.D Whittenberger, and M.H. Yoo, eds., Materials Research Society, Pittsburgh, PA, 1993, vol. 288, pp. 1197-1202

7. E.P. Lautenschlager, D.A. Kiewit, and J.O Brittain: Trans. TMSAIME, 1965, vol. 233, pp. 1297-1302.

8. R.D. Field, D.F. Lahman, and R. Darolia: in High-Temperature Ordered Intermetallic Alloys $V, I$. Baker, R. Darolia, J.D. Whittenberger, and M.H. Yoo, eds., Materials Research Society, Pittsburgh, PA, 1993, vol. 288, pp. 423-28.

9. J.M. Brzeski, J.E. Hack, R. Darolia, and R.D. Field: Mater. Sci. Eng., 1993, vol. Al70, pp. 11-18.

10. C.T. Liu, E.H. Lee, E.P. George, and A.J. Duncan: Scripta Metall Mater., 1994, vol. 30, pp. 387-92.

11. R.T. Pascoe and C.W.A. Newey: Metall Sci. J., 1968, vol. 2, pp. $138-43$.

12. R.T. Pascoe and C.W.A. Newey: Metall. Sci. J., 1971, vol. 5, pp. 5055 .

13. R.D. Noebe, R.R. Bowman, and M.V. Nathal: Int. Mater. Rev., 1993, vol. 38, pp. 193-232

14. M.L. Weaver, V. Levit, M.J. Kaufman, and R.D. Noebe: in HighTemperature Ordered Intermetallic Alloys VI, J.A. Horton, 1. Baker, S. Hanada, R.D. Noebe, and D.S. Schwartz, eds., Materials Research Society, Pittsburgh, PA, 1995, vol. 364, pp. 425-30.

15. M.L. Weaver: Ph.D. Dissertation, University of Florida, Gainesville, FL, 1995.

16. J.M. Brzeski, J.E. Hack, and R. Darolia: in High-Temperature Ordered Intermetallic Alloys VI, J.A. Horton, I. Baker, S. Hanada, R.D. Noebe, and D.S. Schwarz, eds., Materials Research Society, Pittsburgh, PA, 1995, vol. 364, pp. 419-24.

17. J.E. Hack, J.M. Brzeski, and R. Darolia: Scripta Metall. Mater., 1992, vol. 27 , pp. 1259-63.

18. J.M. Brzeski: Ph.D. Dissertation, Yale University, New Haven, CT, 1995

19. M.L. Weaver, M.J. Kaufman, and R.D. Noebe: Intermetallics, 1996, vol. 4, pp. 121-29.

20. M.L. Weaver, R.D. Noebe, J.J. Lewandowski, B.F. Oliver, and M.J Kaufman: Mater. Sci. Eng., 1995, vols. Al92-A193, pp. 179-85.

21. M.L. Weaver, R.D. Noebe, J.J. Lewandowski, B.F. Oliver, and M.J. Kaufman: Intermetallics, 1996, accepted for publication.

22. M.L. Weaver, R.D. Noebe, and M.J. Kaufman: Scripta Mater., 1996, vol. 34 , pp. $941-48$

23. U.F. Kocks: Metall. Trans. A, 1985, vol. 16A, pp. 2109-29.

24. R.J. Wasilewski: Trans. TMS-AIME, 1966, vol. 36, pp . 455-57.

25. R.D. Noebe, R.R. Bowman, and M.V. Nathal: in Physical Metallurgy and Processing of Intermetallic Compounds, N.S. Stoloff and V.K Sikka, eds., Chapman and Hall, New York, NY, 1995, pp. 212-50.
26. D.B. Miracle: Acta Metall. Mater., 1993, vol. 41, pp. 649-84

27. M.L. Weaver, M.J. Kaufman, and R.D. Noebe: Scripta Metall. Mater. 1993, vol. 29, pp. 1113-18.

28. J.S. Winton, A.A. Morrone, V.I. Levit, and M.J. Kaufman: Paper presented at the TMS Fall Meeting, Cleveland, $\mathrm{OH}, 1995$.

29. J.S. Winton, V.I. Levit, and M.J. Kaufman: University of Florida, Gainesville, FL, unpublished research, 1995

30. P. Rodriquez: Bull. Mater. Sci. (India), 1984, vol. 6, pp. 653-63

31. P.G. McCormick: Acta Metall., 1972, vol. 20, pp. $351-54$.

32. S. Venkadesan, C. Phaniraj, P.V. Sivaprasad, and P. Rodriguez: Acto Metall. Mater., 1992, vol. 40, pp. 569-80.

33. E. Pink: Scripta Metall., 1983, vol. 17, pp. 847-52.

34. R.W. Hayes and W.C. Hayes: Acra Metall, 1982, vol. 30, pp 1295-1301

35. J.T. Kim: Ph.D. Dissertation, The University of Michigan, Ann Arbor, Ml, 1990

36. P. Nagpal, I. Baker, and J.A. Horton: Intermetallics, 1994, vol. 2, pp 23-29.

37. P. Nagpal and I. Baker: J. Mater. Lett., 1992, vol. 11, pp. 1209-10

38. J.T. Kim, R.D. Noebe, and R. Gibala: Proc. Int. Symp. of Intermetallic Compounds-Structural and Mechanical Properiies, O. Izumi, ed. Japan Institute of Metals, Sendai, 1991, pp. 591-95.

39. S.C. Tjong and J.S. Zhang: Scripta Metall. Mater., 1995, vol. 32, pp 1589-93.

40. C.L. Cullers, S.D. Antolovich, and R.D. Noebe: in High-Temperature Ordered Intermetallic Alloys $V$, I. Baker, R. Darolia, J.D Whittenberger, and M.H. Yoo, eds., Materials Research Society, Pittsburgh, PA, 1993, vol. 288, pp. 531-36.

41. T. Takasugi, J. Kishino, and S. Hanada: Acta Metall. Mater., 1993, vol. 41, pp. $1009-20$

42. M.A. Crimp, S.C. Tonn, and Y. Zhang: Mater. Sci. Eng., 1993, vol A170, pp. $95-102$

43. Y. Zhang, S.C. Tonn, and M.A. Crimp: in High-Temperature Ordered Intermetallic Alloys $V, 1$. Baker, R. Darolia. J.D. Whittenberger, and M.H. Yoo, eds., Materials Research Society, Pittsburgh, PA, 1993, vol. 288, pp. 379-84.

44. R.D. Field, D.F. Lahrman, and R. Darolia: in High-Temperature Ordered Intermetallic Alloys IV, L.A. Johnson, D.P. Pope, and J.O. Stiegler, eds., Materials Research Society, Pittsburgh, PA, 1991, vol. 213, pp. 255-60.

45. L.P. Kubin and Y. Estrin: J. Phys. III, 1991, vol. 1, pp. 929-43.

46. C.R. Brooks: in ASM Metals Handbook Desk Edition, H.E. Boyer and T.L. Gall, eds., ASM, Metals Park, OH, 1985, pp. 28.66

47. E.T. Stephenson: Trans. TMS-AIME, 1965, vol. 233, pp. 1183-84.

48. M. Koiwa: Phil. Mag., 1971, vol. 24, pp. 81-106.

49. M. Koiwa: Phil. Mag., 1971, vol. 24, pp. 799-814.

50. M. Koiwa: Phil. Mag., 1971, vol. 24, pp. 539-54

51. M. Koiwa: Phil. Mag., 1971, vol. 24, pp. 107-22.

52. R.E. Reed-Hill and T. Zhu: High Temp. Mater. Proc., 1984, vol. 6 , pp. 93-117.

53. R.E. Reed-Hill and M.J. Kaufman: Acta Metall. Mater., 1995, vol. 43, pp. $1731-39$.

54. K.S.B. Rose and S.G. Glover: Acta Metall., 1966, vol. 14, pp. 1505 16.

55. B.K. Zuidema, D.K. Subramanyam, and W.C. Leslie: Metall. Trans A, 1987, vol. 18A, pp. 1629-39.

56. T. Shun, C.M. Wan, and J.G. Byme: Acta Metall. Mater., 1992, vol. 40, pp. 3407-12.

57. J.D. Baird and C.R. Mackenzie: J. Iron Steel Inst., 1964, vol. 202, pp. 427-36

58. J.D. Baird and A. Jamieson: J. Iron Steel Inst, 1966, vol. 204, pp 793-803.

59. J.D. Baird and A. Jamieson: J. Iron Steel Inst., 1972, vol. 210, pp $841-46$.

60. R.L. Klueh and R.E. Oakes, Jr.: J. Eng. Mater. Technol., 1976, vol. 98, pp. 361-68.

61. R.L. Klueh: J. Nucl. Mater., 1977, vol. 68, pp. 294-307.

62. T.C. Chou and T.G. Nieh: Scripta Metall. Mater., 1991, vol. 25, pp. 2059-64.

63. T.C. Chou and T.G. Nich: in High-Temperature Ordered Intermetallic Alloys $I V$, L.A. Johnson, D.P. Pope, and J.O. Stiegler, eds., Materials Research Society, Pittsburgh, PA, 1991, vol. 213, pp. 1045-50.

64. H. Hosoda, K. Inoue, and Y. Mishima: in High-Temperarure Ordered Intermetallic Alloys VI, J. Horton, I. Baker, S. Hanada, R.D. Noebe, and D.S. Schwartz, eds., Materials Research Society, Pittsburgh, PA, 1995, vol. 364 , pp. $437-42$. 
65. I.M. Anderson, A.J. Duncan, and J. Bentley: in High-Temperature Ordered Intermetallic Alloys VI, J. Horton, I. Baker, S. Hanada, R.D. Noebe, and D.S. Schwartz, eds., Materials Research Society, Pittsburgh, PA, 1995, vol. 364, pp. 443-48.
66. R. Danolia, R.D. Field, R.D. Noebe, A. Garg, and W.S. Walston: A Mechanistic Study of Microalloying Effects in NiAl, GE Aircraft Engines/Air Force Office of Scientific Research, Final Report, July 1, 1991-Mar. 31, 1995. 